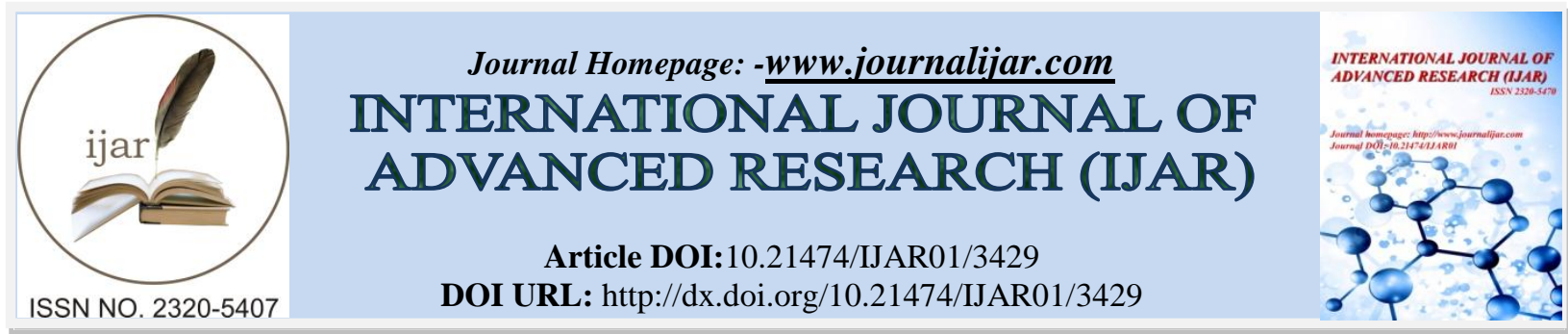

RESEARCH ARTICLE

\title{
EMPLOYER BRANDING AND IT'S IMPACT ON ATTRACTION AND RETENTION IN IT FIRMS: AN EMPIRICAL STUDY.
}

\author{
Prof. Dr. Suruchi Pandey ${ }^{1}$, Bandana Preet Kaur Jolly ${ }^{2}$, Ridhima Bhatia ${ }^{2}$ and Smriti Mishra ${ }^{2}$. \\ 1. Professor, Symbiosis International University. \\ 2. MBA Students, Symbiosis International University.
}

\section{Manuscript Info}

Manuscript History

Received: 14 December 2016

Final Accepted: 16 January 2017

Published: February 2017

Key words:-

Employer Branding, Internal Customers, Employee Value Proposition, Attraction and Retention Strategies.

\section{Abstract}

One of the key sources of competitive advantage today is taken to be talented human capital base. In lieu of the same, different firms have been seen to employ the generic marketing strategies to augment the complete employment experience. In this context, employees are viewed to be 'Internal Customers' and the 'Job' as a product, which the firm offers to its personnel. The practice of adherence to such marketing principles under the purview of human resource management, is today popularly christened as 'Employer Branding'. Given the relevance that the firms today are laying on this concept and the committed efforts initiated by them towards becoming the 'Employer of Choice', is clearly reflective of the significance of this employee friendly strategy. Employer branding is thus defined as "a targeted, long-term strategy to manage the awareness and perceptions of employees, potential employees and related stakeholders with regards to a particular firm" (Sullivan, 2004). It is thus emerging as a potent tool to convey the 'Employee Value Proposition' to existent and plausible recruits. It would be interesting to note that due to such dedicated efforts by varied organizations (spanning versatile industries) the current and potential employees tend to form certain perceptions about the employer brand. This dissertation therefore aims to study certain relevant dimensions of employer branding and their subsequent impact on effectively attracting and retaining, employees. The focused group for collecting data entailed employees currently working in certain prominent IT giants and Business School students who are likely to enter the corporate sector in the upcoming days. A survey was conducted and a total of two hundred responses was collected for subsequent analysis. Further, exploratory factor analysis was undertaken using SPSS for reducing the identified dimensions into certain tangible and relatable factors. It was finally concluded that strategic employer branding has a direct (positive) implication on retaining critical talent pool. Also, branding and other pertinent advertising strategies employed by organizations facilitate in enhancing employer attractiveness for potential hires. Thus, the 'Brand Promise' which the employers of today are extending to their workforce, has been comprehensively discoursed in the paper. 
Copy Right, IJAR, 2017,. All rights reserved.

\section{Introduction:-}

Conventionally, Branding as a concept has often been used to differentiate an organization's products in general over that of its competitors. Today, with the entire transition from an industrial age to a more information oriented age, Branding now is seen from versatile perspectives. From adding economic value to its customers and its other relevant stakeholders, this strategic tool of creating a distinguished identity is now also focused on developing the right attraction and retention policies for its employees. Thus, the new buzz word today is 'Employer Branding' wherein organizations are particularly shifting focus towards creating a positive perception in the minds of the key stakeholders, potential recruits and current employees. Given that this entire initiative involves a mind-set level change, this exercise is definitely a long term one. The term which picked up popularity in the last decade of the previous century, is now adopted by a lot of global organizations as part of their premeditated human resource initiatives. With immense competition in every sphere, the obvious outcome was poaching of critical talent resulting in dearth of an endowed workforce. Perturbed by this growing scarcity of potential recruits, a lot of firms realised the importance of creating lucrative incentives to adequately attract and retain the right talent pool.

At a broader level, branding of such kind entailed dedicated efforts by any organization towards conveying to its current and potential employees that it is a 'desirable place to work'. The 'Pre-eminent Employer' image is something all organizations strive for, clearly highlighting the value addition they perceive with this entire exercise. The leadership of esteemed organizations are evidently aware of how requisite investment in skillful human resources can bring in long term gains thereby subsequently enhancing the overall performance of the organization. It is thus a wholesome package which is offered to an employee whether it is in terms of the economic gain (lucrative salary packages and equitable income opportunities), the functional upliftment (through training and managerial facilitation) or the most pertinent of all, the psychological contract (sense of autonomy at workplace).

There are certain minimal expectations that any employee has out of his/her employment today. These anticipations could vary from a suitable organization culture, to lucrative pay packages, streamlined job activities, right job fitment and managerial effectiveness. Keeping this view in mind, two sets of questionnaires were prepared. One questionnaire entailed seventeen variables, selected for data collection from employees of renowned IT firms. The intention was to cater to the 'retention' element of the intended research. The respondents had to rate the relevance of the identified variables in regards to their contribution towards creating a differentiated brand. The second questionnaire comprised of questions directed towards students in their final year of management degree. The objective behind selecting this particular sample of respondents was to gather their opinion around what 'attracts' them to opt for a given employer brand over the other. A total of eighteen variables were considered in this case which were mostly overlapping with the first questionnaire but with the addition of certain relevant variables which were fitting contextually. The rankings were done on a Likert Scale ranging from 'Very Important' to 'Unnecessary'. These were further ramped up with certain demography related questions. Finally, to determine crucial 'psychographic aspects', an exploratory factor analysis was conducted on the collected data set.

\section{Problem Statement:-}

In increasingly competitive labour markets of today, attracting and retaining critical talent has become a matter of grave concern. Employers need to understand the range of factors that influence career decision making and in particular the role of employer branding in attracting the 'best fit' employee who would subsequently contribute towards the premeditated goals of an organisation. The problem therein lies in trying to understand the impact and relevance of employer branding as an essential element of attraction and retention strategies and devise suitable ways through which companies could maximise their brand awareness in the employment market.

\section{Objective ofthe Study:- Primary Objective:-}

To understand the nature of relationship between employer brand image and employee attraction and retention.

\section{Specific Objective:-}

1. To identify and list certain attributes that make up a 'desirable' employer, subsequently creating a strong, genuine and lasting employer brand.

2. To understand as to what extent the branding strategies implemented by IT firms impact the potential recruits' decision about joining the firm. 


\section{Hypothesis 1:-}

- H0 (Null Hypothesis): Strategic Employer Branding does not have any role to play towards retaining employees in a firm.

- H1 (Alternate Hypothesis): Strategic Employer Branding reinforces the entire employment experience thereby positively influencing the retention levels within a firm.

\section{Hypothesis 2:-}

- H0: Branding and advertising strategies do not lead to attracting employees with superior skills and knowledge.

- H1: Branding and advertising activities executed as part of the recruitment experience positively impact the candidate pool; thereby leading to better potential recruits.

\section{Review of Literature:-}

Employer Branding as a concept has gained importance in recent times. As an ideology, it can be said that this is an extension of the conventional marketing principles which primarily focused on generating the requisite customer satisfaction (Gupta, 2014). While until recently, the entity 'customer' comprised of individuals external to the organization, the paradigm shift in employer mind-set has resulted in introduction of the concept of an 'internal customer' (Chhabra \& Sharma, 2014). The apparent question which now arises is that who are these internal customers and why are organizations today willingly ready to prioritize them over their revenue generating counterparts.

In the rampant competitive business environment of today, the only logical answer to this question is that these customers are none other than the organization's personnel. (Lievens \& Highhouse, 2003). The rationale necessitates that if an employee is considered to be a customer then in all likelihood the product in question is the Job which he/she is currently or likely to be associated with in the future. The Job as a product should therefore be able to attract, inspire, develop, satisfy and retain employees. Further, a strategic value chain would ensure that a contented employee serves the customer (external) satisfactorily (Moroko, 2008).

Building further on this value proposition it can be said that employer branding is about providing an all comprehensive employment experience. Now, while this might sound an execution level strategy, it first and foremost requires a visionary leadership (Pingle \& Sharma, 2013). Leaders who not only understand the value addition that a talented workforce brings to the table, but also have the conviction to deal with the nuances of this imperative change. Further, these front runners are the ones who would set the culture rolling thereby empowering the people on the ground to devise and execute differentiated human resource practices (Priyadarshi, 2011). The alignment of branding strategies with HR practices might therefore be a long drawn process but once set in the right direction is likely to have only positive implications (Tuzuner \& Yuksel, 2009).

A renowned employer brand would invariably maintain its position in the competitive labour market through attractive engagement and retention initiatives, thereby resulting in unquestionable brand loyalty. Given the magnitude of impact and benefit this particular exercise is likely to generate, it is definitely not a trivial undertaking (Buttenberg, 2013). A phased approach of implementation needs to be followed and the first critical step is realising the unique value proposition that the firm in question has to offer. The differentiating factor thus identified needs to be broken down into relevant attributes/dimensions in order to further determine the core values/characteristics that set the organization apart. Once your latent strengths and weaknesses have been identified, the next important step entails understanding in-depth your probable target audience. This involves identifying current and potential recruits who are currently/or are likely to be associated with your brand. This would enable the firm to effectively communicate its value proposition internally as well as externally, instigating the requisite level of affinity in the bargain. Once you are successful in 'selling' your brand in a righteous manner, the next logical step is to actually fulfil the promise that you have made to your (internal) customers and ensure that your image of a virtuous employer continues to remain intact (Davies, 2008).

A strong employer marque can thereby result in two immediately realisable benefits. First, ensuring that the right set of talent is 'attracted' towards the organization and second that the desirable 'retention' levels are maintained. 'Employer attractiveness' in very simplistic terms can be defined as the anticipated benefits that are perceived to be realisable by current or plausible workforce, thereby motivating them to choose one brand over the other in the competitive labour market. 
Thus, this notion is closely associated with the behavioural and psychological traits of any individual, thereby making it an interesting research area for far too many academicians and corporate managers (Alnıçık \&Alnıaçık, 2012).

Further, this bond which is created through a persuasive brand image, also contributes towards retaining employees for a longer duration of time. The benefits might invariably be intangible but the compelling sense of belongingness which surfaces eventually, is enough to ensure continuum loyalty. Hence, it can be said without doubts that a lucrative 'Employee Value Proposition' is a potent tool for becoming the employer of choice (Agrawal \& Swaroop, 2009).

While these tactics have been popularly adopted across the board, one of the most prevalent industries which puts this perception to effective use, is that of Information Technology (IT). A reasonable explanation for this could be the fact that the IT industry is essentially 'people driven' and hence establishing the indispensable psychological contract with its people, is of utmost importance to them. Further, it can also be said that since the industry practices involve client facing roles and responsibilities, a highly convinced and dedicated employee is critical for their survival (Jenner and Taylor, 2009). An employee who is likely to stick around inspite of the dynamic work environment, is the one who would eventually generate concrete economic benefits for them. Thus, professed to be one of the most employable business, firms in IT industry have been actively involved in executing employer branding strategies. The endeavour has been to ensure that the employee's ethics and values are in perfect alignment with the broader vision and mission of the organization, thereby ensuring that these individuals are developed into innate brand ambassadors for the firm in question. Given the immense potential for study in this domain, the researchers decided to niche down the scope to IT industry (Ritson, 2002).

Another interesting facet of this research work is the bifurcation which has been made in relation to the respondents which have been targeted. While one segment constitutes of existent employees who have been successfully retained within firms due to certain employer branding initiatives, the other section comprises of students who are latent recruits for such organizations. Students are often expected to be lured by hefty pay packages and other tangible benefits but past research work in the domain has proved otherwise. While compensation may be a supreme decision criterion related to their employment, students are also often seen to consider a variety of other facades (Dam, 2006). These could include dimensions such as an established corporate profile or effective advertisement/promotional strategies that are adopted by their potential employers. Thus, such predictive factors that motivate recruits to apply for a particular job vacancy, is still an unopened Pandora box in the research field. The current study thus attempts to bring to the forefront such underlying aspects, in the bargain, answering certain critical questions for the managers of giant IT organizations (Vijayalakshmi\& Uthayasuriyan, 2016).

\section{Research Methodology:-}

Pilot Study:-

In order to gauge the feasibility of the intended research, a pilot study was instigated. Keeping in mind the overall objectives of the study, two questionnaires were framed. These were then filled out by 10 respondents per questionnaire ( $10 \%$ of total sample size).

Based on the analysis of the responses from the identified stakeholders and discussions/deliberations within the team, the authenticity of the established hypothesis was discussed. This enabled us to reinstate our intention to conduct further research in the recognised domain.

\section{Sample Details:-}

- A field visit was undertaken across certain renowned brands in the field of Information Technology.

- The Sample Size comprised of 100 respondents (employees working in IT firms, specifically targeting new recruits and employees who are part of middle level management). A healthy male to female ratio was maintained while collecting the responses.

- A separate Sample of 100 respondents was collected which comprised of Student Managers currently pursuing their post-graduation study from reputed B-Schools in the city.

\section{Data Collection Tool:-}

The data collected for this study primarily constitutes of the following two sources: 
- Primary Data: Primary data collection has been the principal mode of enquiry. It entailed collecting data through two well-structured questionnaires consisting of twenty or more questions which essentially aimed at bringing out relevant information to meet the overall objectives of the research. The responses were filled out in a hard copy format as the survey was personally conducted by the researchers in each of the aforementioned areas.

- Secondary Data: Data which is originally collected for a different purpose but we use it as reference for our research work, encompasses secondary data. Various sources of secondary data collection comprised of journals, newspapers, databases and previously published papers available over the internet.

\section{Validation of Hypothesis:-}

Once the relevant data had been gathered, the researchers undertook quantitative analysis of the same -

\section{Quantitative Analysis:-}

The survey results were used to scientifically and objectively classify the data using certain commonly used tools such as Statistical Package for the Social Sciences (SPSS) and Microsoft Excel.

For detailed analysis/interpretation of the survey results, certain appropriate tests were run using SPSS and relevant conclusions were made thereon. In order to validate the authenticity of the alternate hypothesis certain psychographic dimensions were considered and a Factor Analysis was done on them to club them under relevant Factor heads.

To get further insights pertaining to our hypothesis, appropriate excel formulas, charts and graphs were also used. This enabled us to further infer and test the applicability of the existing hypothesis.

Moreover, since the research work has been a field study, the researchers were also be able to come up with a concrete outlook based on the observations they made pertaining to the employee/student behaviour (while they responded to the questions asked). Such kind of analysis can be condensed under the umbrella of 'Observations through being Participant in actual Field Study' methodology which later also towards building our overall opinion about the study.

To measure the qualitative responses, such as those related to the respondent's feelings, perception, likes, dislikes, interests and preferences, the scaling technique has been used.

For this research, a type of an interval scale, known as a Likert scale, was incorporated in the questionnaire. This measurement scale was developed by Rensis Likert. Under this, the respondents were asked to indicate a degree of agreement or disagreement to a series of statements. Each scale item had five response categories ranging from 'Very Dissatisfied' to 'Very Satisfied'.

\section{Data Analysis and Interpretation:-}

The subsequent pages display certain graphical representations along with related discussions based on the survey results.

\section{Part 1:- Student Questionnaire.}

Age:-

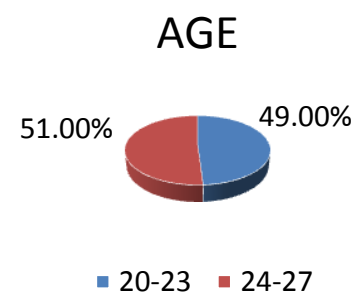

Fig 1:-Age of the Respondents.

Out of the 100 respondents, $51 \%$ of the students interviewed were in the age group of $20-23$ years and $49 \%$ of the students belonged to the age group of 24-27 years. 


\section{Gender:-}

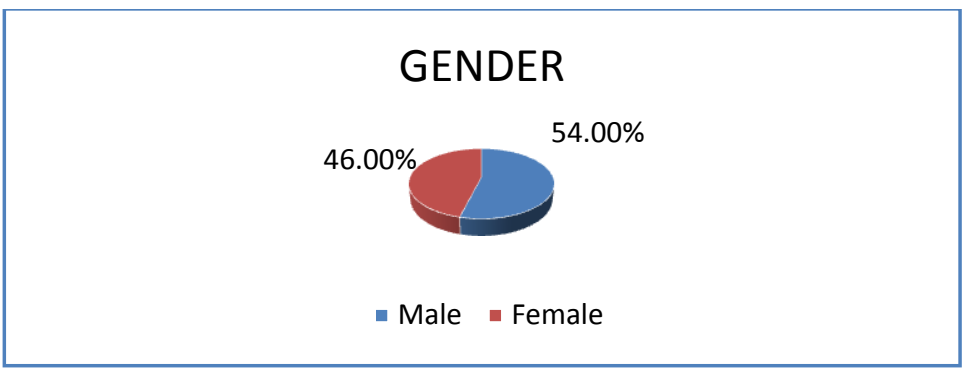

Fig 2:-Gender of the Respondents.

Out of the 100 students surveyed, $46 \%$ were female and $54 \%$ were male.

\section{Location:-}

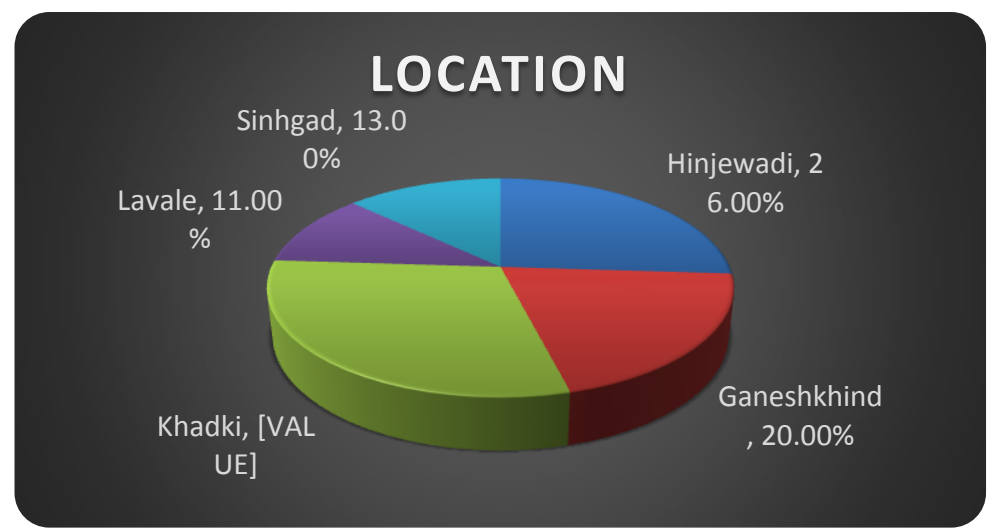

Fig 3:- Location of the Respondents

It was observed that out of the 100 respondents, majority of the respondents were from the B-Schools in Khadki, Hinjewadi, and Ganeshkhind consisting of 30\%, 26\% and 20\% of total respondents respectively.Other B-Schools comprised of $13 \%, 11 \%$ of total respondents.

\section{Concern towards Employees:-}

\section{CONCERN TOWARDS EMPLOYEE}

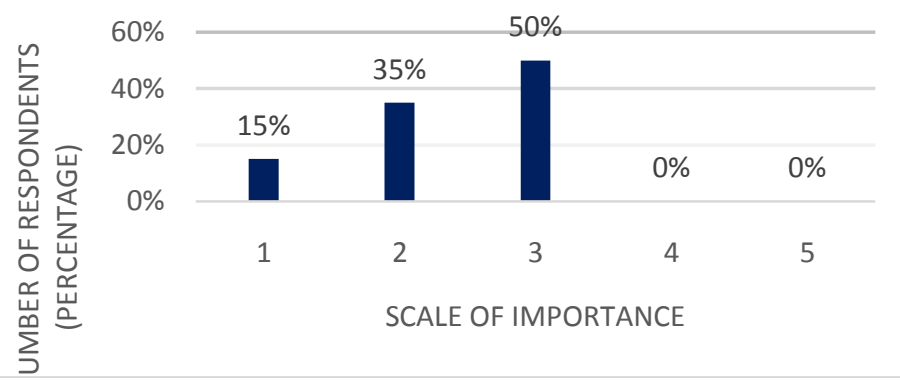

Fig a:- Concern towards employees.

\section{Discussion:-}

The above figure represents responses of students in regards to the work environment of an organization, particularly about 'concern towards employees'.

The figure illustrates that $50 \%$ of the students have given a neutral response to concern towards employees. It is not the most important factor that affects their attrition or retention although 35\% of the students feel it is an important factor which is considered by them. Only $15 \%$ students feel that this factor holds a lot of importance and have 
responded to it as a very important factor. No respondent states that this factor is either not important or unnecessary stating that every student considers it a relevant factor while selecting their future employer.

\section{Investment in training and Development:-}

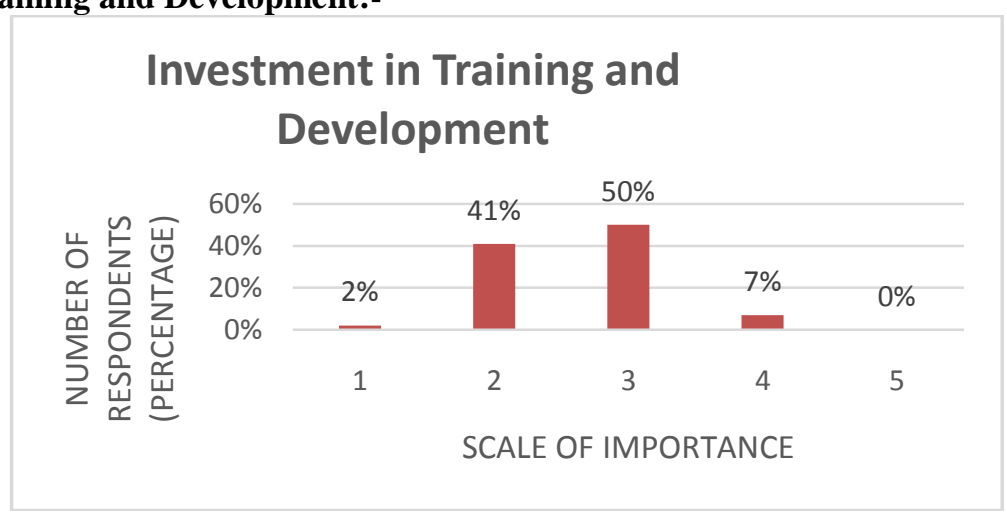

Fig b:-Investment in training and development.

\section{Discussion:-}

The above figure represents the level of importance a student attributes to investment in training and development by its plausible future employer.

The figure elucidates that $50 \%$ of the students take a neutral position while demonstrating the importance given to investment in training and development whereas $41 \%$ of the respondents find it an important factor. Only $2 \%$ of the respondents find it to be a very important factor. There are no students who state that training and development is unnecessary and does not impact their decision making.

\section{Job/role rotation frequency:-}

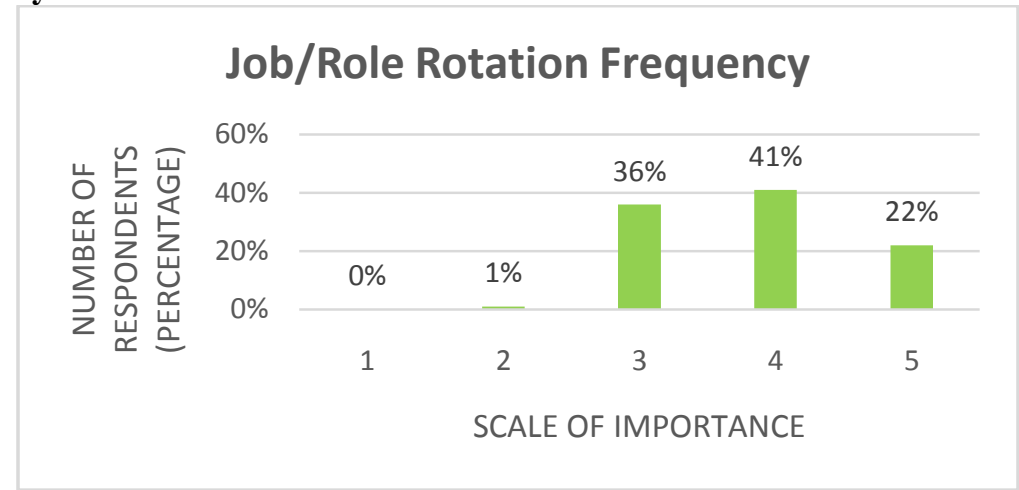

Fig c:-Job/role rotation frequency.

\section{Discussion:-}

It is observed that most students after MBA do not consider job/role rotation a dominant factor while selecting their future company and find job rotation and mobilization acceptable.

The figure states that $41 \%$ of the employees do not find this an important factor while $36 \%$ of the respondents have given a neutral response to it. While $22 \%$ of the respondents find this as an unnecessary factor, there is however no student that finds it a very important or most important factor. 
Openness in organizational culture:-

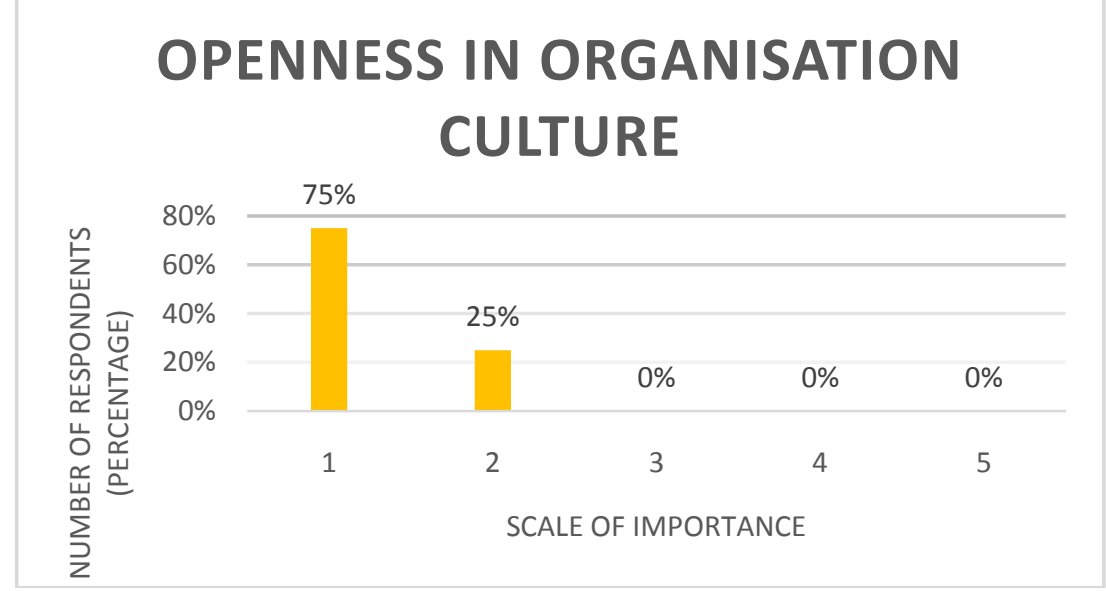

Fig d:- Openness in organizational culture.

\section{Discussion:-}

It is observed that openness in the organizational culture holds high importance amongst individuals while selecting their future company.

The above figure depicts that $75 \%$ of the respondents find it important to have openness in the organizational culture while $25 \%$ find it to be a very important factor. There are no students with a neutral, not important or an unnecessary response in regards to this variable.

Freedom to take up initiatives:-

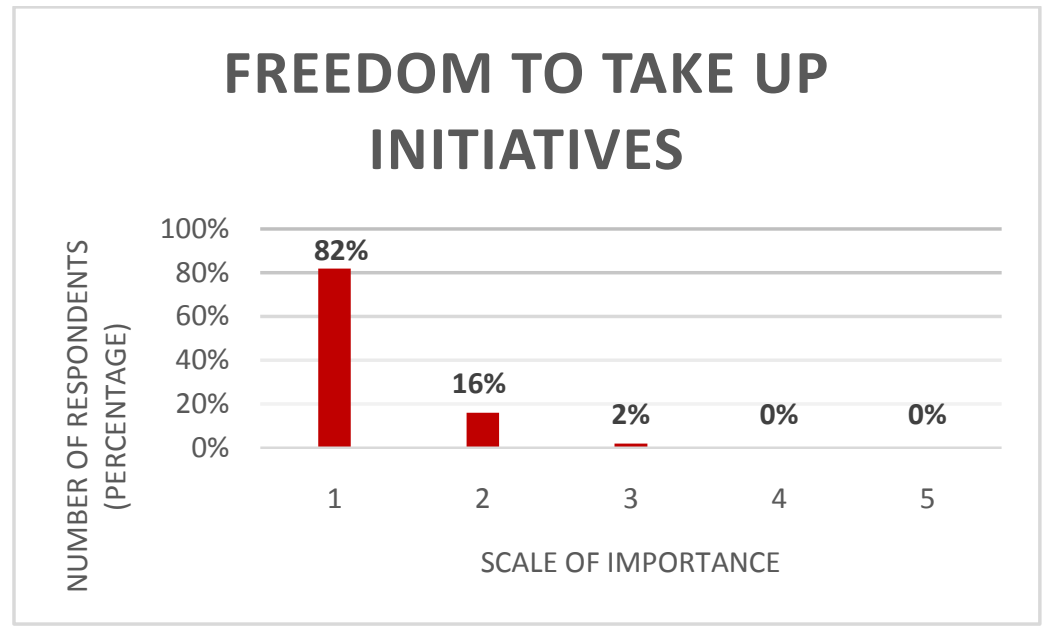

Fig e:- Freedom to take up initiatives.

\section{Discussion:-}

With the newer generation entering the corporate sector we can see the paramount importance provided to and the need amongst them to take up initiatives on their own.The above figure depicts the same by illustrating that $82 \%$ of the employees give very high importance to having freedom to take up their own initiatives. This is one of the major factors that affects their decision while selecting their future employer while $16 \%$ of the respondents find it important with $25 \%$ giving a neutral response to it. No respondent finds freedom to take up initiatives not important or unnecessary. 


\section{Salary hikes:-}

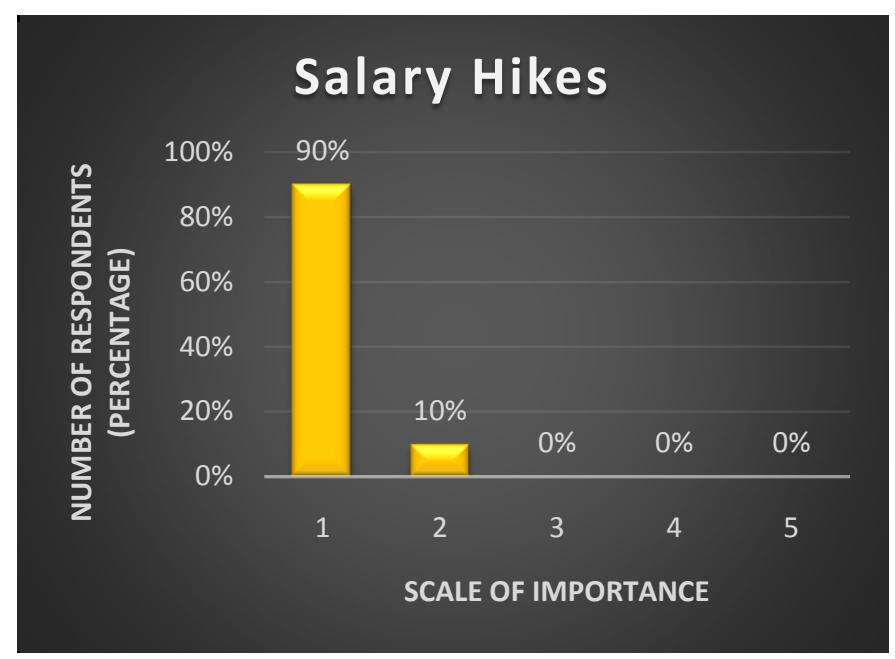

Fig f:-Salary hikes.

\section{Discussion:-}

It can be observed by the above figure that regular salary hikes are and important variable considered by students while choosing their future hirer.

$90 \%$ of the respondents have stated it to be very important factor while $10 \%$ state it to be important. No respondent has provided a neutral, not important or unnecessary factor response in this scenario.

\section{Internal and external equity in pay determination:-}

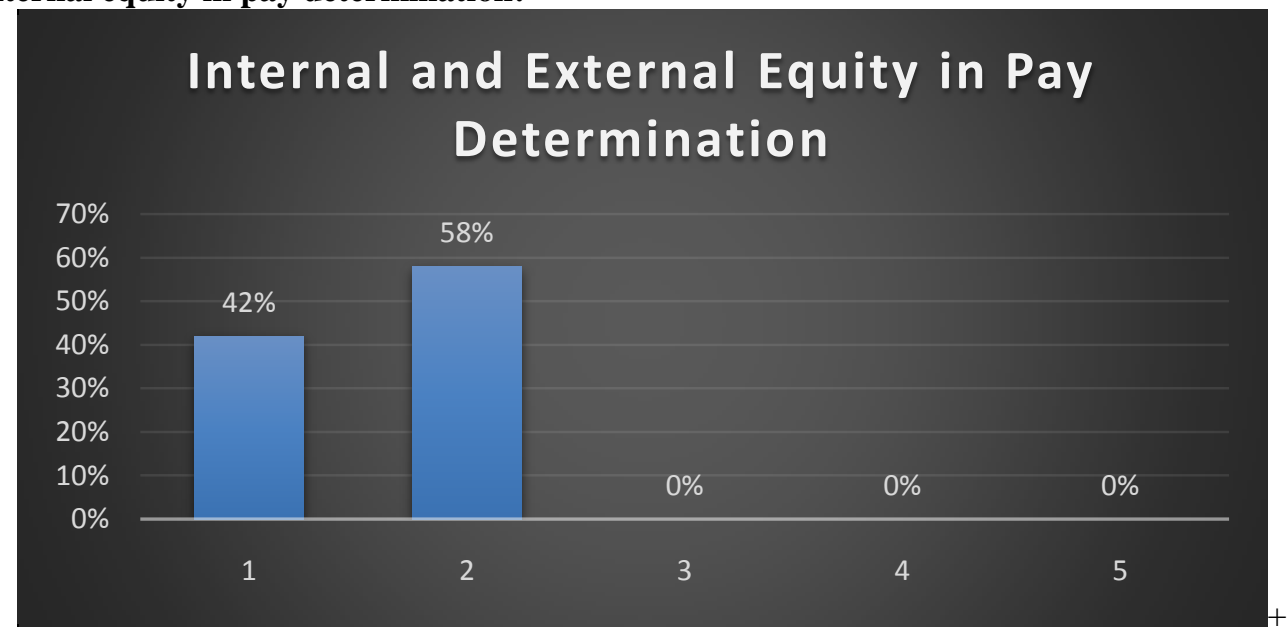

Fig g:- Internal and external equity in pay determination.

\section{Discussion:-}

The above figure states that internal and external equity in pay determination holds high value for students as $58 \%$ of the students have considered it to be an important factor while selecting their future employer with $42 \%$ stating it as a very important factor.

No respondent considers this factor to be neutral, not important or unnecessary. 
Management's contribution towards employee career planning:-

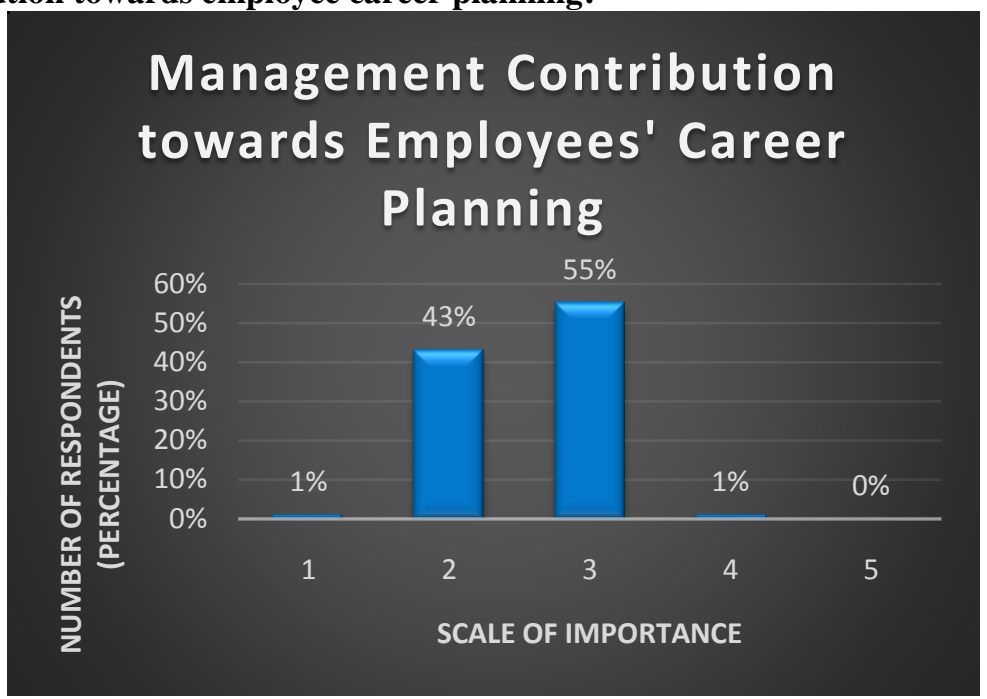

Fig h:-Managements contribution towards employee career planning.

\section{Discussion:-}

It can be seen that maximum respondent's i.e.55\% students have provided a neutral response to this factor. Being the first company post MBA, it is very unlikely for the respondents to continue in the said firm for a very long time and thus management's contribution in career planning holds a neutral spot while $43 \%$ of the respondents find it an important factor. $1 \%$ response is recorded for both very important and not important with no one responding to it as an unnecessary factor.

Opportunities for International work assignments:-

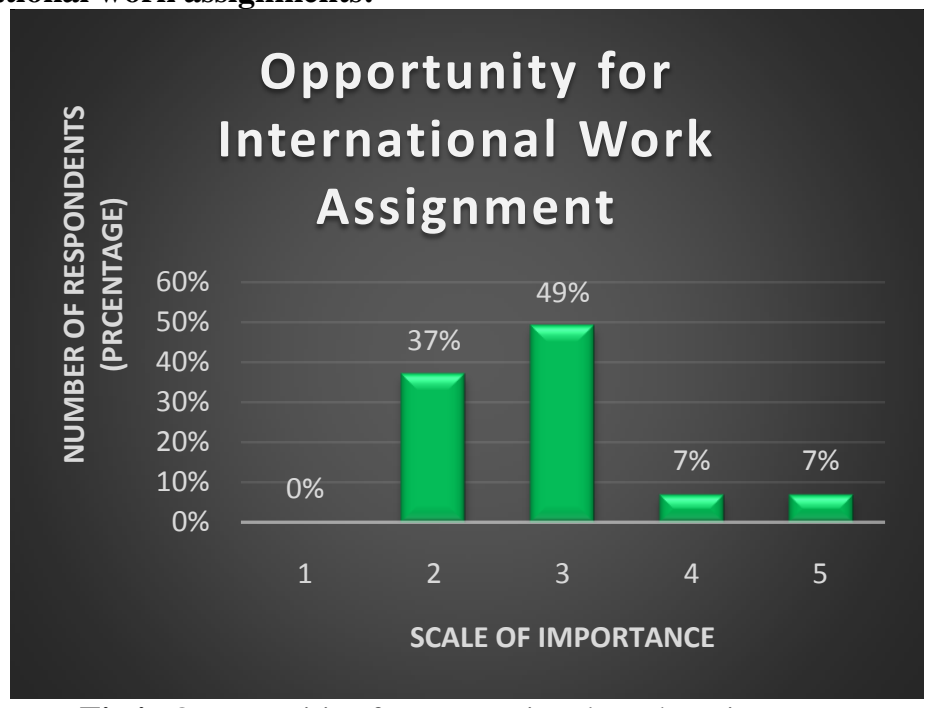

Fig i:-Opportunities for International work assignments

\section{Discussion:-}

It can be observed by the figure above that maximum respondents i.e. $49 \%$ of them find it a neutral factor that plays a role while selecting their employer while $37 \%$ of them find it an important factor that is considered while decisionmaking. $7 \%$ of the responses have been recorded for both not important and an unnecessary factor. No respondent finds this factor as very important. 
Size of the organization:-

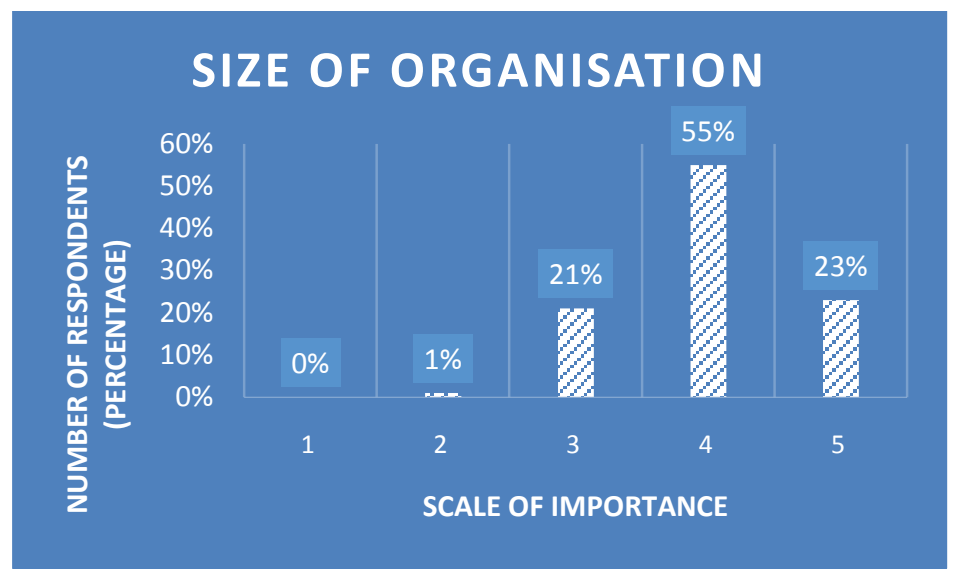

Fig j:- Size of the organization

\section{Discussion:-}

It is observed that $55 \%$ of the respondents do not consider the size of the organization an important factor while selecting their future employer while $23 \%$ consider it an unnecessary factor.

$21 \%$ of the respondents have given a neutral response to this with only $1 \%$ finding it important.

No respondents considers this to be a very important factor.

\section{Stress-free work environment:-}

\section{STRESS-FREE WORK ENVIRONMENT \\ ENVIRONMENT}

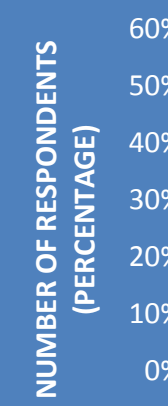

$60 \%$

$50 \%$

$40 \%$

$30 \%$

$20 \%$

$10 \%$

$0 \%$

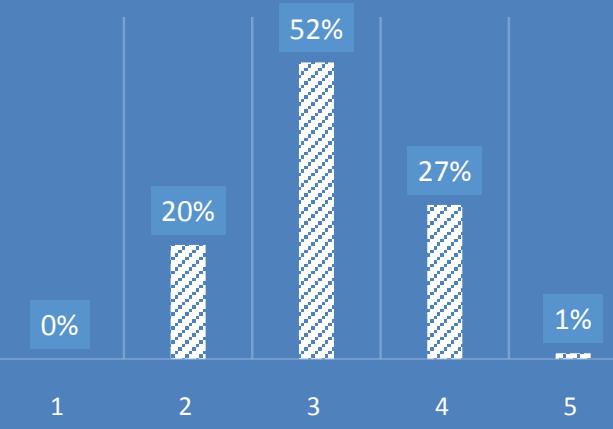

SCALE OF IMPORTANCE

Fig k:-Stress-free work environment

\section{Discussion:-}

It can be seen that students do not consider a stress free work environment very crucial with $52 \%$ giving a neutral response to it and $27 \%$ finding it not important as they feel they can handle and work well in stress.

$20 \%$ respondents do consider it an important factor while only $1 \%$ finds it unnecessary and no responses have been recorded for this factor to be highly important. 


\section{Employer prestige in market place:-}

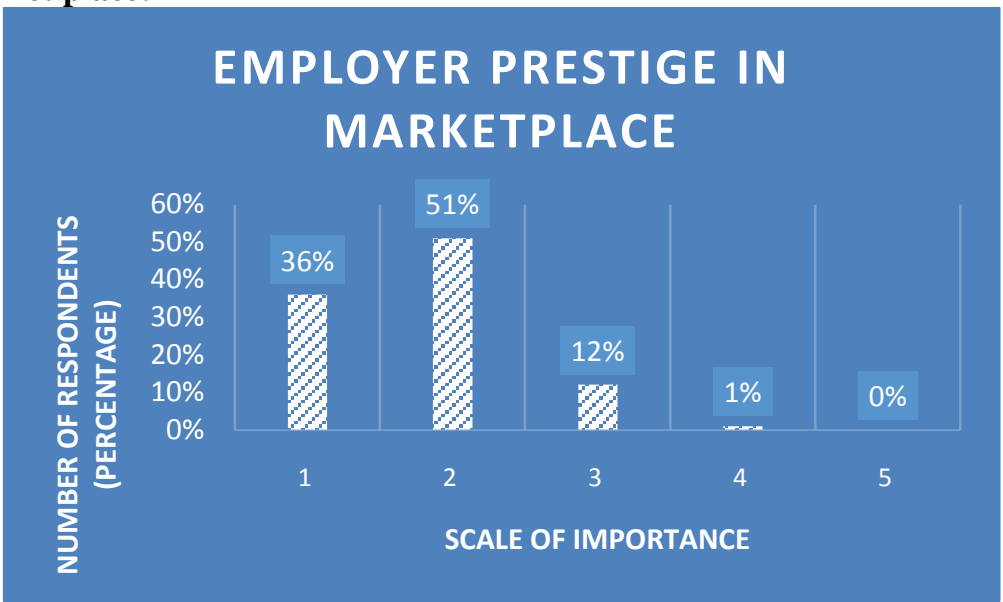

Fig l:-Employer prestige in market place.

\section{Discussion:-}

Employer prestige and the brand name holds high dominance for the respondents.

It can be observed that maximum respondents i.e. 51\% of the students find it an important factor while deciding and selecting their future employer with $36 \%$ of the students find it a very important factor, thus making this as one of the major factors influencing the decision taken.12\% of the respondents have provided a neutral response with only $1 \%$ response for it being not important.

No respondent has stated that it is an unnecessary factor.

\section{Scope for creativity in work assigned:-}

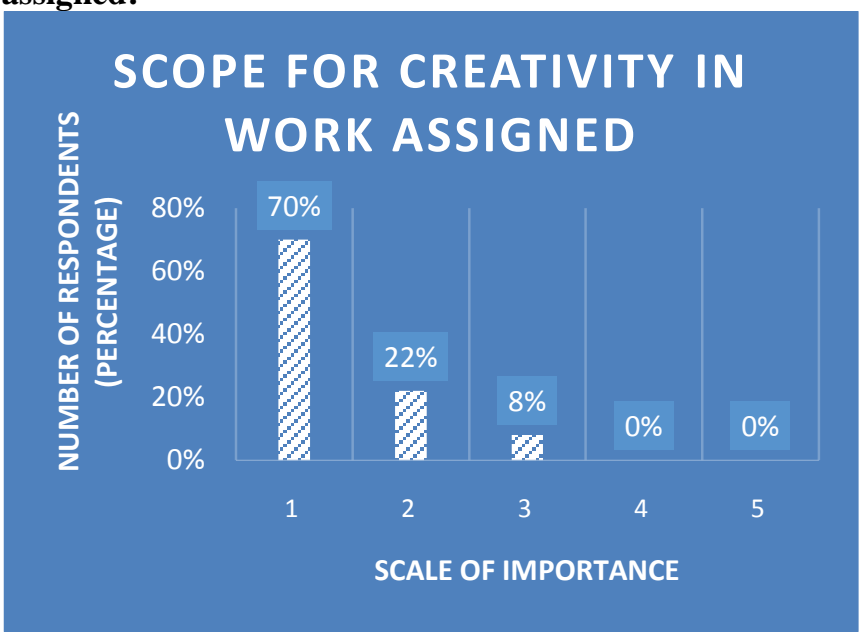

Fig m:-Scope for creativity in work assigned

\section{Discussion:-}

It can be observed from the above figure that respondents find it necessary to have scope of creativity in any project they handle with $71 \%$ of them stating it to be a very important factor with $22 \%$ of them finding it important.

Only $8 \%$ of the respondents have given a neutral response to creativity as a criterion. No respondent finds this factor not important or unnecessary stating that scope of creativity in work is crucial. 
Social media presence (Networking through Facebook, Twitter, and LinkedIn):-

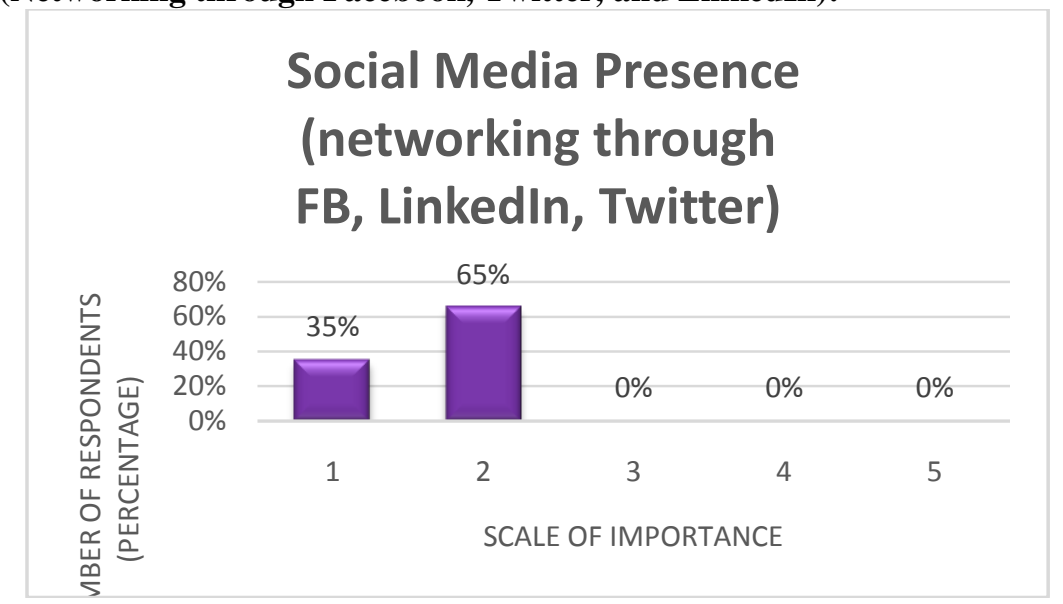

Fig n:- Social media presence (Networking through Facebook, Twitter, LinkedIn)

\section{Discussion:-}

All respondents find social media presence a major influencer and attractor while selecting future hirers.65\% of the respondents hold this factor as an important one with $35 \%$ of the respondents finding it a very important factor.

No respondent considers it to be neutral, not important or unnecessary stating the high significance of social medial marketing.

Word-of-mouth reputation through ex-employees:-

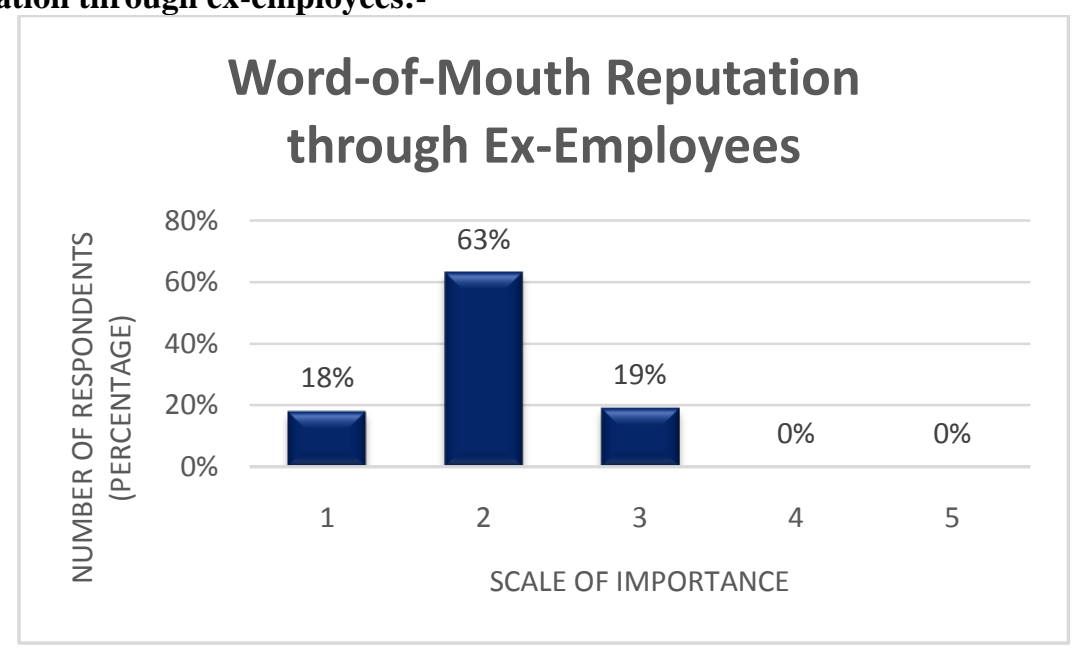

Fig o:-Word-of-mouth reputation through ex-employees

\section{Discussion:-}

Maximum respondents consider word of mouth advertising before taking their employment decision. The above figure states that $63 \%$ of the employees consider this to be an important factor before they make their decision with $18 \%$ finding it very important and 19\% giving a neutral response. No response has been recorded for this factor to be not important or unnecessary thus depicting its major influence on respondents. 
Print and electronic advertisements:-

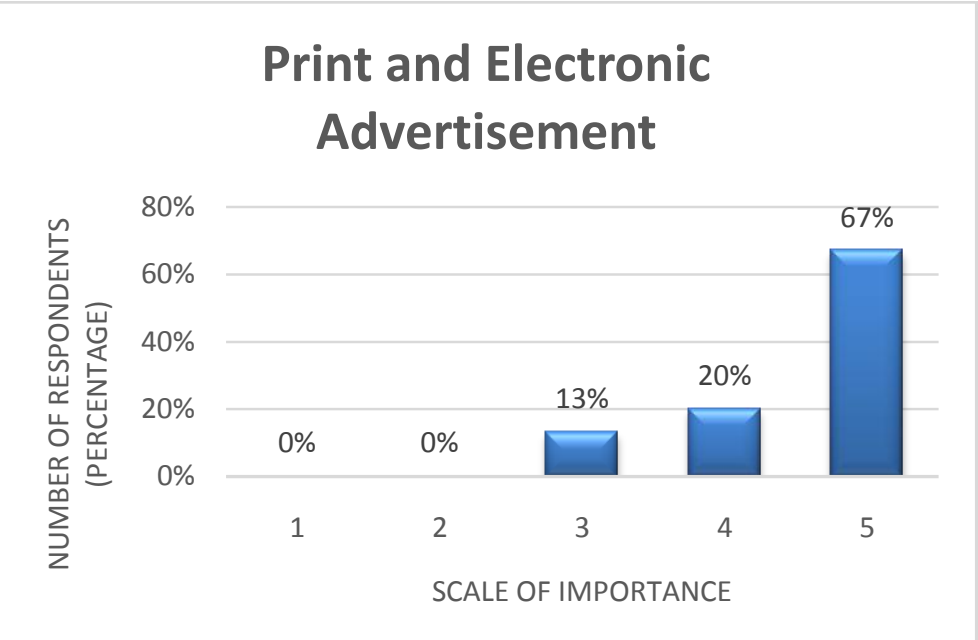

Fig p:- Print and electronic advertisements.

\section{Discussion:-}

It is observed that print and electronic advertisements do not hold much value now-a-days. It can be confirmed by the figure shown above depicting $67 \%$ respondents finding it unnecessary with $20 \%$ finding it not important and $13 \%$ responding to it as neutral.

No respondent considers this to be an important or very important factor while selecting their future employers.

Reach-out during relevant seminars, conferences and webinars:-

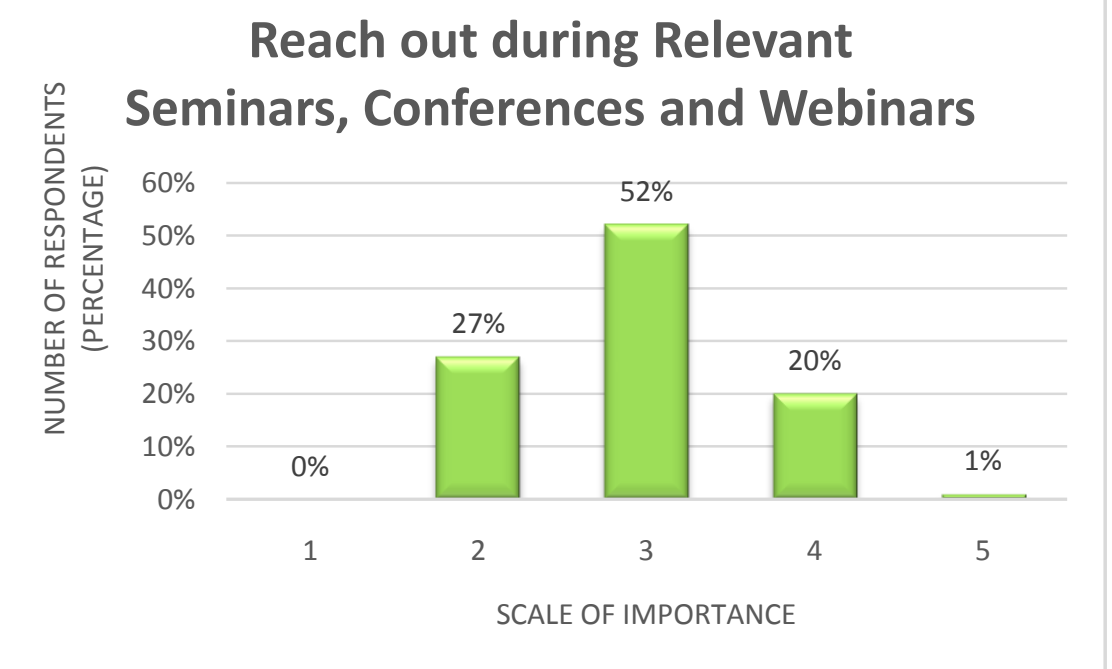

Fig q:-Reach-out during relevant seminars, conferences and webinars.

\section{Discussion:-}

The above figure states that $52 \%$ of the respondents find this factor to be a neutral influencer with $27 \%$ finding it important.

$20 \%$ of the respondents do not find it important and $1 \%$ find it as an unnecessary parameter.

No respondent finds it to be a very important factor. 
Prevalent market image as a virtuous employer:-

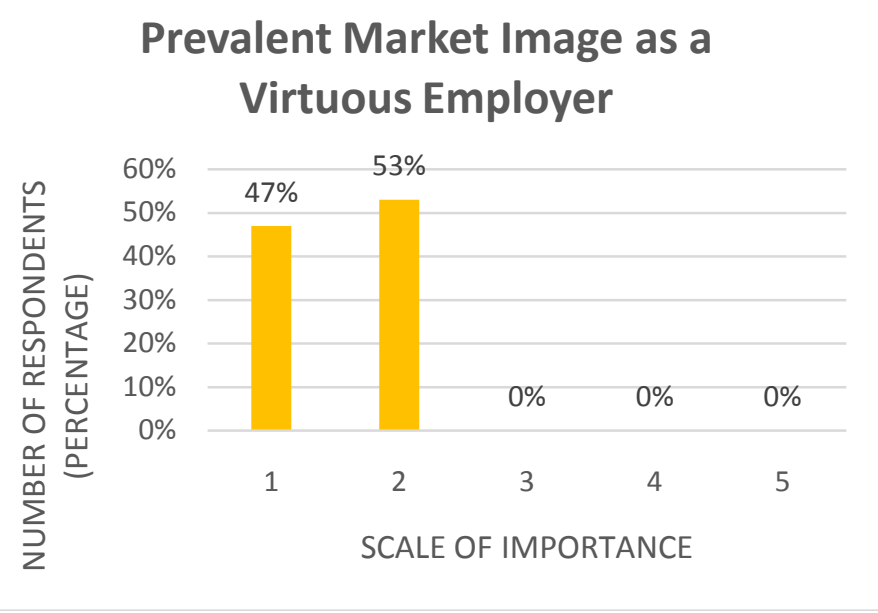

Fig r:- Prevalent market image as a virtuous employer.

\section{Discussion:-}

All respondents find it important for their selected employer to have a prevalent market image as a virtuous employer with 53\% finding it important and $47 \%$ finding it a very important factor.

How relevant do you feel is branding and advertising strategy in attracting better potential recruits?

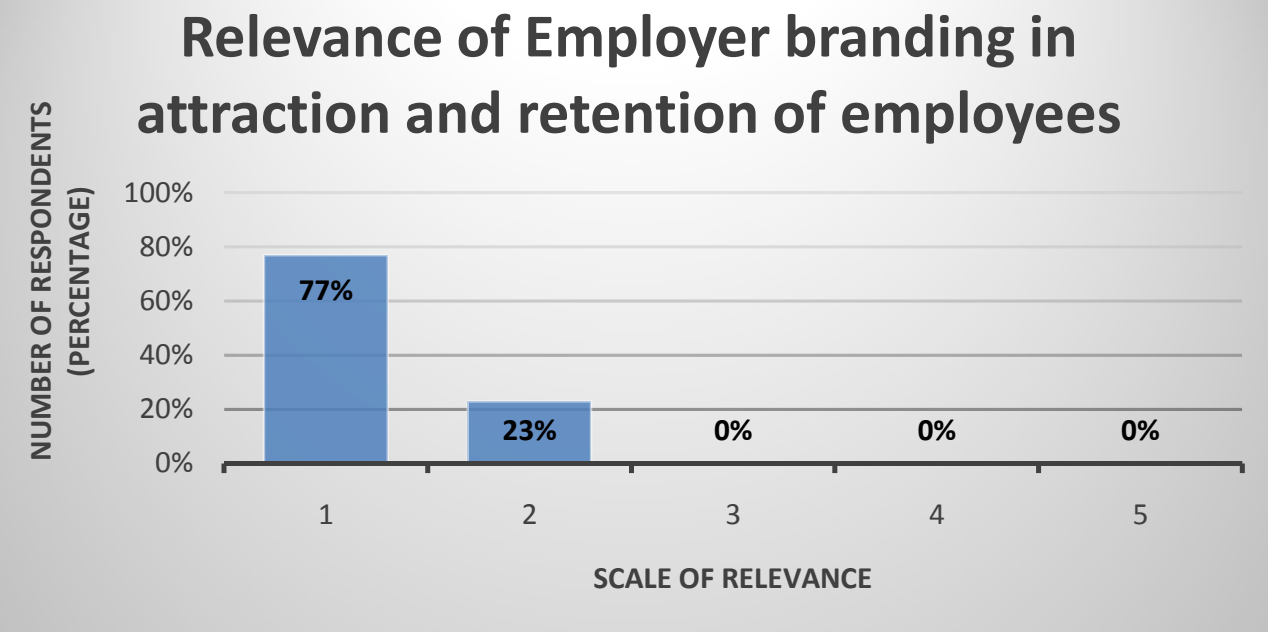

Fig 4:-Relevance of employer branding in attraction and retention of employees

\section{Discussion:-}

Majority of the respondents feel that employer branding plays a major role in attracting and retaining employees in an organization.

It can be observed from the figure that $77 \%$ of the respondents find employer branding very relevant for attracting and retaining employees with $23 \%$ finding it an important factor.

Are there any specific parameters that would motivate you to select a particular organization over the others?

Majority of the respondents look into organization's social media presence and word-of-mouth (through exemployees) before selecting a particular organization over others.

Job specific training sponsored by the company augments the inclination towards a future employer. Career management seems to have an influence on the perceived quality of employment experience. Working conditions 
influence the entire working experience increasing overall satisfaction of employees. Other specific parameters being stable growth and remuneration prospects offered by the organization, transparency in leadership decision making and open culture of the organization. Thus, these are the factors which play a dominant role while a prospective employee makes decisions about his/her future employment.

\section{Part 2:- Employee Questionnaire}

Age:-

\section{Age (in years) (100 responses)}

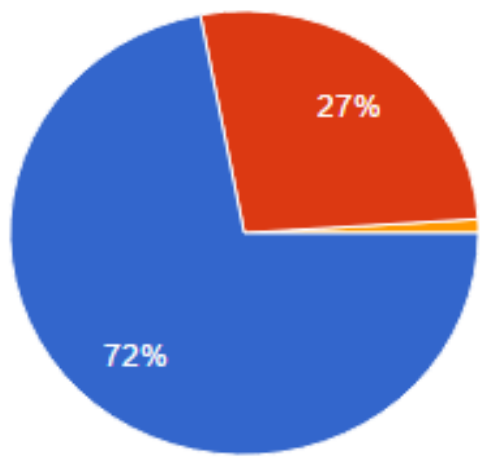

Fig 1:-Age of the Respondents

As evident in the graph above, $72 \%$ of the respondents belonged to the age bracket of 21-28 years. The intention was to capture the responses of freshers/young professionals working in the IT sector. On the other hand, $27 \%$ of the respondents belonged to the age bracket of 29-36 years which constitutes the middle management layer of the respective organizations.

\section{Gender:-}

\section{Gender (100 responses)}

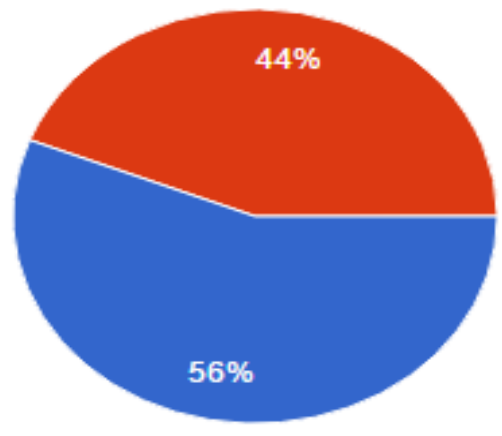

Male

Female

Fig 2:- Gender of the Respondents.

The above male to female ratio is reflective of the general diversity ratio observed in the organizations which have been considered. While this ratio was once dominated by the male counterparts, it can be seen from the above figure that there is a definite alteration in the conventional trends and thus today the female professionals are as much part of the private sector jobs as their male colleagues. 
The prominent parameters which came out from the study include:-

Investment in training and development

1. b) Investment in Training and Development (100 responses)

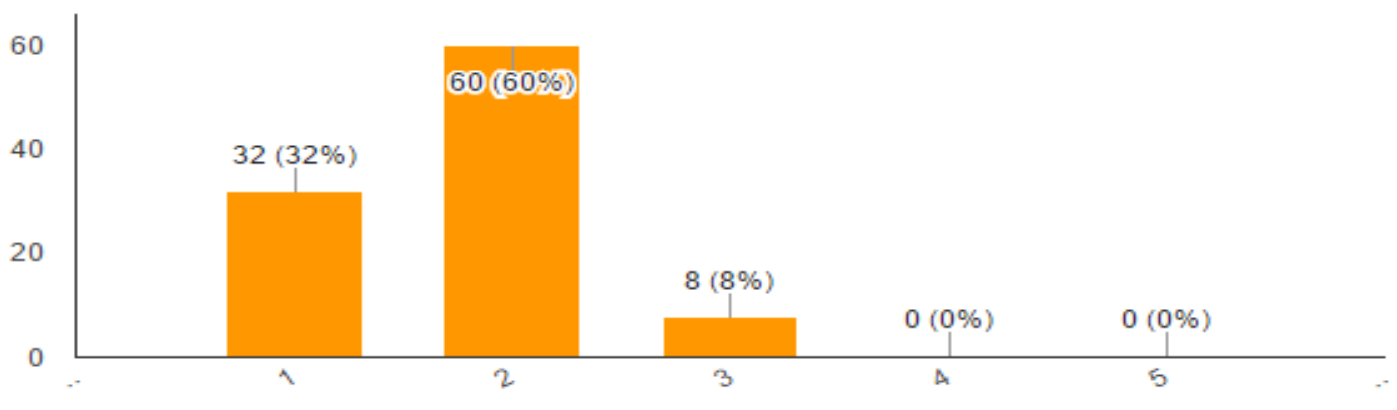

Note: $\mathrm{X}$ axis is to measure the scale of importance while percentage of respondents has been assimilated in $\mathrm{Y}$ Axis

Fig a:- Investment in training and development

\section{Discussion:-}

Majority of the respondents (60\%) weresatisfiedwiththe current exposure to requisite Training and Development programs and thus considered it as one of the prime parameters to be considered while evaluating the internal brand image of an employer.

Freedom totake up initiatives:-

\section{1. e) Freedom to Take Up Initiatives (100 responses)}

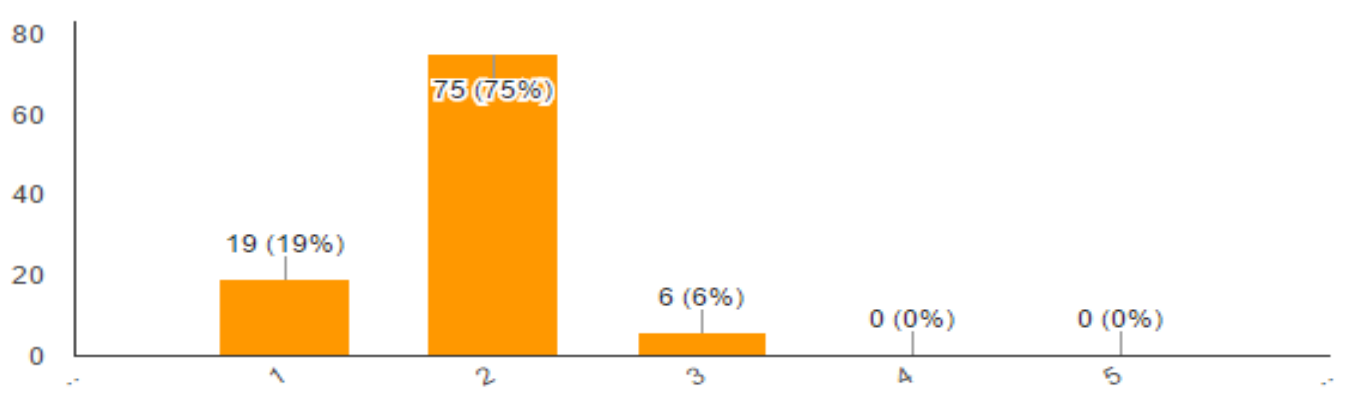

Note: $\mathrm{X}$ axis is to measure the scale of importance while percentage of respondents has been assimilated in $\mathrm{Y}$ Axis

Discussion:-

Fig b:- Freedom to take up initiatives.

Majority of the Respondents (75\%) rated Freedom to take up initiative as a very high parameter towards satisfaction in their respective employment. This is clearly indicative of how autonomy at workplace can play a prime role in retaining employees in an organization. 
Workforce diversity:-

2. b) Workforce Diversity (100 responses)

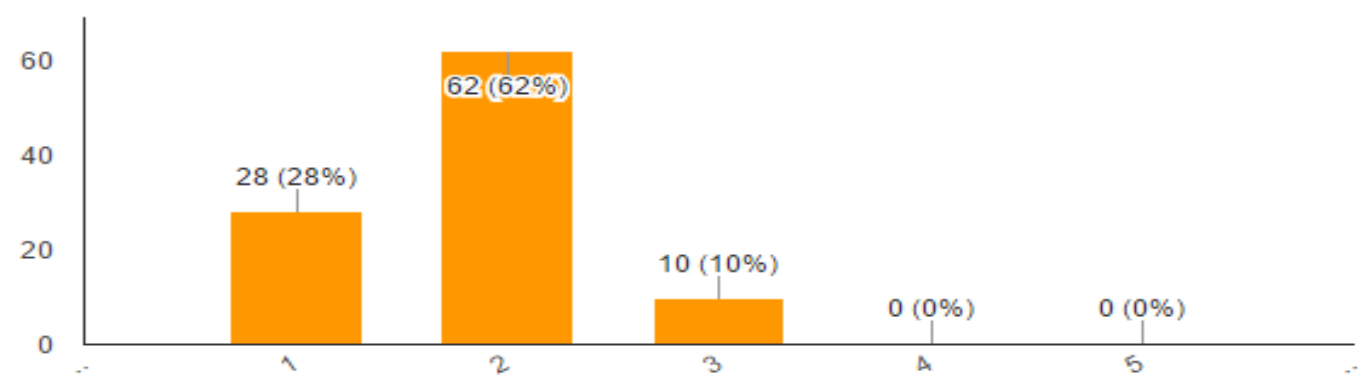

Note: $\mathrm{X}$ axis is to measure the scale of importance while percentage of respondents has been assimilated in $\mathrm{Y}$ Axis

Fig c:-Workforce diversity.

\section{Discussion:-}

Majority of the respondents (62\%) were of the opinion that workforce diversity definitely helps the organization in establishing a renowned brand image. Diversity at workplace shows that the organization is open to versatility in its talent pool and is cognizant towards the importance of maintaining a healthy balance in the male - female ratio.

\section{Internal and external equity in pay determination:-}

\section{3. b) Internal and External Equity in Pay Determination (100 responses)}

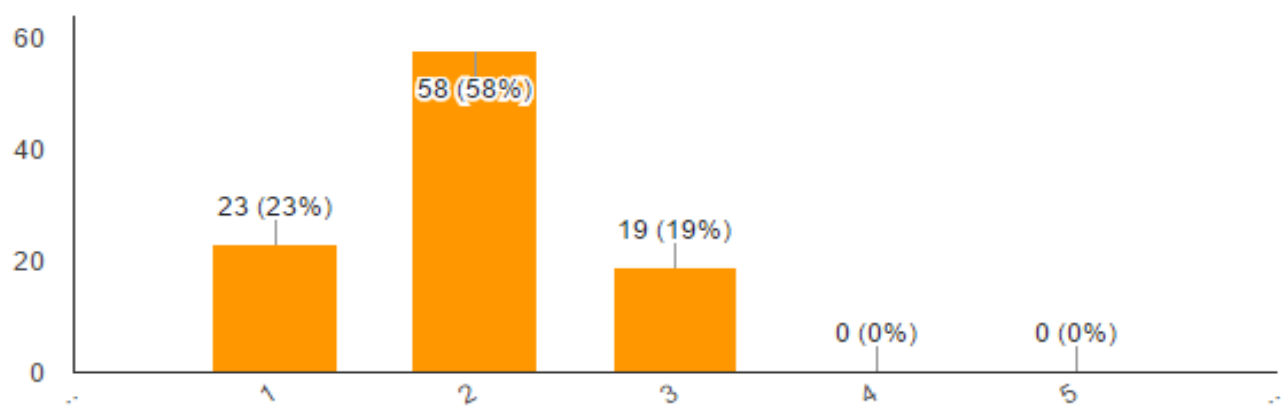

Note: $\mathrm{X}$ axis is to measure the scale of importance while percentage of respondents has been assimilated in $\mathrm{Y}$ Axis

Fig d:-Internal and external equity in pay determination

\section{Discussion:-}

Majority of the respondents (58\%) were satisfied with the kind of time and investment their respective organizations were making towards maintaining internal and external equity during pay-outs. Ensuring that the salary/increments/yearly bonus are marked to market,is extremely important in today's competitive business environment. This ensures that the respective firm does not lose out on its critical talent. Benchmarking salaries also helps in attracting the best-in-class talent when it comes to recruitment. 
Employer prestige in marketplace:-

\section{4. c) Employer Prestige in Marketplace (100 responses)}

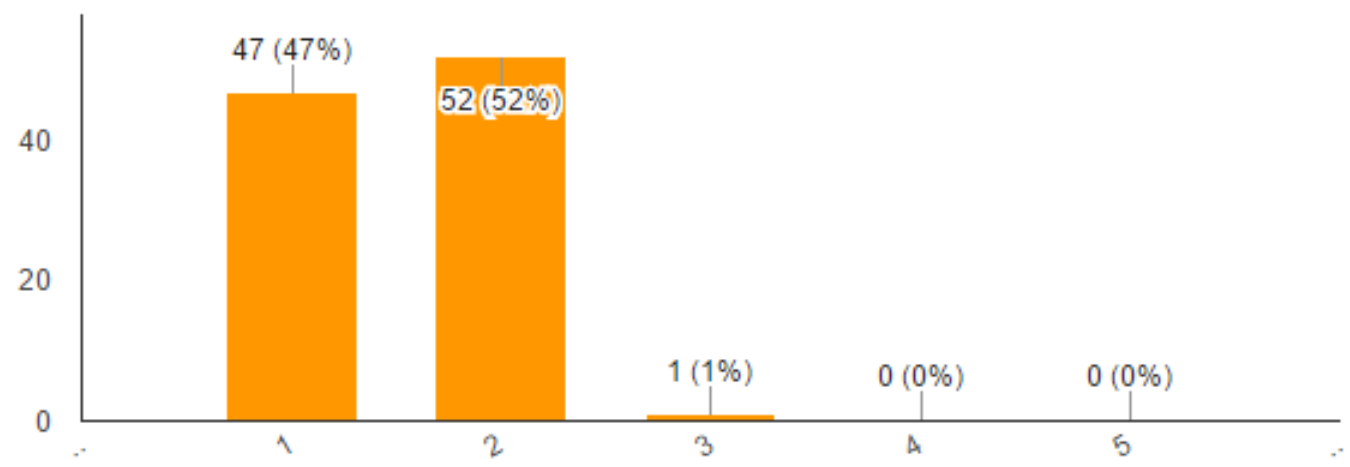

Note: $\mathrm{X}$ axis is to measure the scale of importance while percentage of respondents has been assimilated in $\mathrm{Y}$ Axis

Fig e:- Employer prestige in marketplace.

\section{Discussion:-}

The above figure is clearly indicative of the fact that a significant portion of the respondents were extremely satisfied in regards to the prestige of their organization in the IT industry. This evident inclination brings out the fact that an established and well-known brand in the market place is a definite plus point when it comes to attraction and retention of employees.

How relevant do you feel is strategic employer branding towards ensuring enhanced retention levels within the firm?

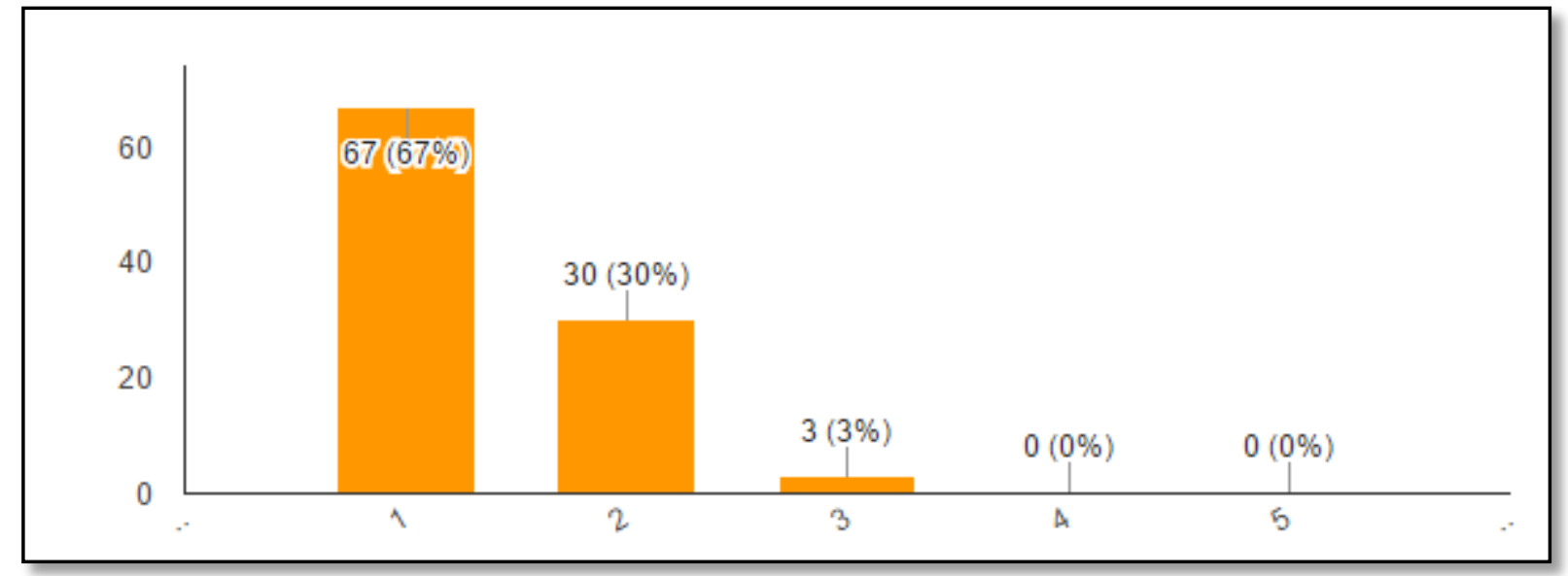

Note: $\mathrm{X}$ axis is to measure the scale of importance while percentage of respondents has been assimilated in $\mathrm{Y}$ Axis

Fig 3:-Relevance of strategic employer branding towards ensuring enhanced retention levels.

\section{Discussion:-}

$67 \%$ of the respondents felt that employer branding is extremely important in attracting and retaining employees in an organisation. Further, $30 \%$ of the respondents were of similar opinion. The results seen above are in definite alignment with the primary objective of the entire research which is being conducted. 


\section{Are there any specific parameters that would motivate you to stay loyal towards your current job?}

\section{Discussion:-}

Certain concrete parameters which came out through this particular question include: higher education facilitation, work life balance, brand name/market standing of the organization, opportunities to handle diversified portfolio, transparency in leadership decision making, progressive culture (at par with market dynamics), variability in routine job - more exposure, benefits to cater for diversity at workplace, opportunities to upscale skill-sets and access to versatile profiles within the organization.

The above factors are essentially responsible for preferring one organization over the other. Successful incorporation of the above factors also result in differentiating a virtuous employer from other several employers in the marketplace.

\section{Hypothesis Validation:-}

The employee questionnaire consisted of certain relevant variables which reinforce the entire employment experience thereby positively influencing the retention levels within a firm. A total of seventeen such variables were considered and Factor Analysis was done on them (using the SPSS tool) in order to club these variables under broader factors. The intention has been to define certain relevant factors which would have a direct implication on retention levels within a firm.

Under factor analysis, we do not make any categorical distinction between a dependent and an independent variable. Infact the relationship between each of the independent variables are studied to be able to classify them under common heads based on certain commonalities which may exist. Thus, a set of procedures are conducted to examine the relationship between a set of interdependent variables with a broader objective of data reduction and summarization.

In this context, factor analysis would help us to determine the underlying factors which according to the employees have a crucial role to play while establishing a renowned employer brand.

Before we delve into the results of the factor analysis which was conducted, it is important to highlight the steps which were followed to do the same.

First and foremost the objective behind conducting the analysis was set, which in our case is to try and point out certain relevant variables which according to employees of certain renowned IT giants are required to ensure that they stay loyal to their respective organizations. Further, the KMO and Bartlett's test of Sphericity helps us to understand if the variables are adequately correlated with each other and whether or not Factor Analysis is relevant in the given situation. A value greater than 0.5 and significance level equivalent to 0.00 indicates that it is acceptable to process with Factor Analysis for further examination. Further, Varimax method of rotation is selected and the requisite procedure is executed.

The variables that were considered as part of the employee survey are as follows -

1. Concern towards Employees

2. Investment in Training and Development

3. Job/Role Rotation Frequency

4. Openness in Organization Culture

5. Freedom to take-up Initiatives

6. Variation in Routine Work

7. Workforce Diversity

8. Work as per Pre-determined Schedule

9. Relevance of Academic Degree

10. Salary Hikes

11. Internal and External Equity in Pay Determination

12. Management Contribution towards Employees' Career Planning

13. Opportunities for International Work Assignments

14. Size of Organization

15. Stress - Free Work Environment 
16. Employer Prestige in Marketplace

17. Scope for Creativity in Work Assigned

The 100 employees who were surveyed across versatile roles/profiles were asked to rate these variables in terms of their relevance towards creating the image of a virtuous employer. The ratings were given on a scale of 1 to 5 varying from Very Relevant to Irrelevant. These were then entered in SPSS to conduct Factor analysis. The result of the same is as follows -

\section{Factor Analysis}

KMO and Bartlett's Test

\begin{tabular}{|c|c|c|}
\hline \multicolumn{2}{|c|}{ Kaiser-Meyer-Olkin Measure of Sampling Adequacy. } & .620 \\
\hline Bartlett's Test of & Approx. Chi-Square & 316.365 \\
\hline Sphericity & df & 136 \\
\hline & Sig. & .000 \\
\hline
\end{tabular}

\begin{tabular}{|c|c|c|}
\hline \multicolumn{3}{|c|}{ Communalities } \\
\hline & Initial & Extraction \\
\hline $\begin{array}{l}\text { ConcernTowardsEmploy } \\
\text { ees }\end{array}$ & 1.000 & .420 \\
\hline $\begin{array}{l}\text { InvestmentInTrainingAnd } \\
\text { Development }\end{array}$ & 1.000 & .644 \\
\hline $\begin{array}{l}\text { JobRoleRotationFrequen } \\
\text { cy }\end{array}$ & 1.000 & .643 \\
\hline $\begin{array}{l}\text { OpennessinOrganization } \\
\text { Culture }\end{array}$ & 1.000 & .661 \\
\hline $\begin{array}{l}\text { FreedomToTakeUpInitiati } \\
\text { ves }\end{array}$ & 1.000 & .637 \\
\hline VariationInRoutineWork & 1.000 & .491 \\
\hline WorkforceDiversity & 1.000 & .624 \\
\hline $\begin{array}{l}\text { WorkAsPerPreDetermine } \\
\text { dSchedule }\end{array}$ & 1.000 & .746 \\
\hline $\begin{array}{l}\text { RelevanceOfAcademicDe } \\
\text { gree }\end{array}$ & 1.000 & .684 \\
\hline SalaryHikes & 1.000 & .698 \\
\hline $\begin{array}{l}\text { InternalAndExternalEquity } \\
\text { InPayDetermination }\end{array}$ & 1.000 & .470 \\
\hline $\begin{array}{l}\text { ManagementContribution } \\
\text { TowardsEmployeesCare } \\
\text { erPlanning }\end{array}$ & 1.000 & .472 \\
\hline $\begin{array}{l}\text { OpportunityForinternation } \\
\text { alWorkAssignment }\end{array}$ & 1.000 & .607 \\
\hline SizeOfOrganization & 1.000 & .630 \\
\hline $\begin{array}{l}\text { StressFreeWorkEnvironm } \\
\text { ent }\end{array}$ & 1.000 & .670 \\
\hline $\begin{array}{l}\text { EmployerPrestigelnMarke } \\
\text { tplace }\end{array}$ & 1.000 & .636 \\
\hline $\begin{array}{l}\text { ScopeForCreativitylnWork } \\
\text { Assigned }\end{array}$ & 1.000 & .832 \\
\hline
\end{tabular}




\begin{tabular}{|c|c|c|c|c|c|c|c|c|c|}
\hline \multirow[b]{3}{*}{ Component } & \multicolumn{9}{|c|}{ Total Variance Explained } \\
\hline & \multicolumn{3}{|c|}{ Initial Eigenvalues } & \multicolumn{3}{|c|}{ Extraction Sums of Squared Loadings } & \multicolumn{3}{|c|}{ Rotation Sums of Squared Loadings } \\
\hline & Total & $\%$ of Variance & Cumulative $\%$ & Total & $\%$ of Variance & Cumulative $\%$ & Total & $\%$ of Variance & Cumulative $\%$ \\
\hline 1 & 2.797 & 16.450 & 16.450 & 2.797 & 16.450 & 16.450 & 2.216 & 13.035 & 13.035 \\
\hline 2 & 2.270 & 13.356 & 29.806 & 2.270 & 13.356 & 29.806 & 2.157 & 12.690 & 25.725 \\
\hline 3 & 1.769 & 10.405 & 40.211 & 1.769 & 10.405 & 40.211 & 1.642 & 9.658 & 35.383 \\
\hline 4 & 1.385 & 8.147 & 48.358 & 1.385 & 8.147 & 48.358 & 1.635 & 9.618 & 45.000 \\
\hline 5 & 1.254 & 7.377 & 55.735 & 1.254 & 7.377 & 55.735 & 1.552 & 9.131 & 54.132 \\
\hline 6 & 1.091 & 6.419 & 62.154 & 1.091 & 6.419 & 62.154 & 1.364 & 8.022 & 62.154 \\
\hline 7 & .922 & 5.422 & 67.576 & & & & & & \\
\hline 8 & .812 & 4.777 & 72.353 & & & & & & \\
\hline 9 & .783 & 4.607 & 76.960 & & & & & & \\
\hline 10 & .667 & 3.926 & 80.886 & & & & & & \\
\hline 11 & .641 & 3.772 & 84.658 & & & & & & \\
\hline 12 & .549 & 3.230 & 87.888 & & & & & & \\
\hline 13 & .494 & 2.908 & 90.796 & & & & & & \\
\hline 14 & .469 & 2.756 & 93.552 & & & & & & \\
\hline 15 & .399 & 2.346 & 95.898 & & & & & & \\
\hline 16 & .378 & 2.223 & 98.120 & & & & & & \\
\hline 17 & .320 & 1.880 & 100.000 & & & & & & \\
\hline
\end{tabular}

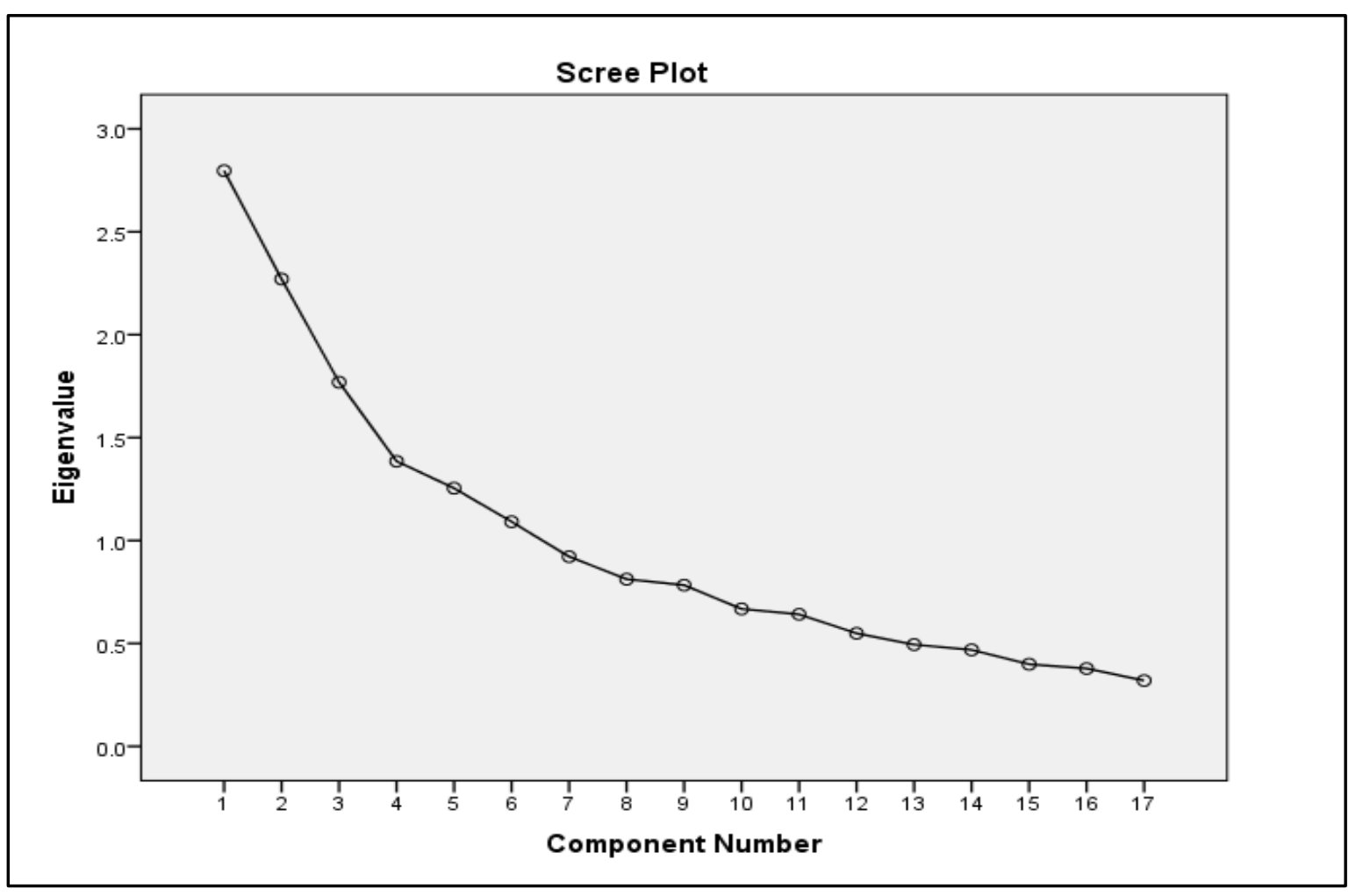




\begin{tabular}{|c|c|c|c|c|c|c|}
\hline \multicolumn{7}{|c|}{ Rotated Component Matrix } \\
\hline & \multicolumn{6}{|c|}{ Component } \\
\hline & 1 & 2 & 3 & 4 & 5 & 6 \\
\hline $\begin{array}{l}\text { ConcernTowardsEmploy } \\
\text { ees }\end{array}$ & .041 & .296 & .561 & .099 & .006 & .079 \\
\hline $\begin{array}{l}\text { InvestmentInTrainingAnd } \\
\text { Development }\end{array}$ & .676 & -.016 & .277 & .040 & -.059 & .323 \\
\hline $\begin{array}{l}\text { JobRoleRotationFrequen } \\
\text { cy }\end{array}$ & .304 & .126 & .346 & .641 & -.034 & .052 \\
\hline $\begin{array}{l}\text { OpennessInOrganization } \\
\text { Culture }\end{array}$ & -.167 & -.054 & .715 & .224 & .233 & -.123 \\
\hline $\begin{array}{l}\text { FreedomToTakeUpInitiati } \\
\text { ves }\end{array}$ & .449 & -.179 & .583 & -.067 & -.183 & .160 \\
\hline VariationInRoutineWork & .656 & .092 & -.085 & -.063 & -.192 & .063 \\
\hline WorkforceDiversity & -.023 & -.023 & .209 & -.123 & .653 & -.370 \\
\hline $\begin{array}{l}\text { WorkAsPerPreDetermine } \\
\text { dSchedule }\end{array}$ & -.015 & .205 & -.044 & .079 & .818 & .163 \\
\hline $\begin{array}{l}\text { RelevanceOfAcademicDe } \\
\text { gree }\end{array}$ & -.294 & .125 & -.320 & .613 & .037 & .321 \\
\hline SalaryHikes & .115 & -.065 & .191 & .784 & -.003 & -.169 \\
\hline $\begin{array}{l}\text { InternalAndExternalEquity } \\
\text { InPayDetermination }\end{array}$ & .455 & .359 & .159 & .209 & .193 & -.167 \\
\hline $\begin{array}{l}\text { ManagementContribution } \\
\text { TowardsEmployeesCare } \\
\text { erPlanning }\end{array}$ & .385 & .514 & .000 & .111 & .180 & .126 \\
\hline $\begin{array}{l}\text { OpportunityForlnternation } \\
\text { alWorkAssignment }\end{array}$ & -.232 & .659 & .177 & -.142 & .224 & -.131 \\
\hline SizeOfOrganization & -.018 & .772 & -.094 & .089 & .124 & .035 \\
\hline $\begin{array}{l}\text { StressFreeWorkEnvironm } \\
\text { ent }\end{array}$ & -.696 & .228 & .104 & -.236 & -.187 & .177 \\
\hline $\begin{array}{l}\text { EmployerPrestigelnMarke } \\
\text { tplace }\end{array}$ & .043 & .687 & .085 & -.007 & -.393 & .016 \\
\hline $\begin{array}{l}\text { ScopeForCreativitylnWork } \\
\text { Assianed }\end{array}$ & .095 & -.011 & .065 & -.037 & -.019 & .904 \\
\hline
\end{tabular}

\section{Inferences:-}

A 'KMO' (Kaiser-Meyer-Olkin measure of sampling adequacy) value of 0.620 indicates that Factor Analysis is the relevant process to be conducted. Once it has been established that Factor Analysis is appropriate in the context, we move on to choose the various approaches within it. In this case, we selected the Principal Component Analysis method, in which the total variance spanning the data set is considered. The factors thus derived our termed as Principal Components. The next table is the 'Communality' table which indicates the magnitude of variance each variable shares with all other variables considered. The next important outcome is the 'Total Variance Explained' table. The 'Initial Eigen Values' / or simply Eigen Values given in the table are values that give us the variance explained by each factor. The variance attributed to each factor is in decreasing order of magnitude (as seen in the table).

Under this approach, only factors with values greater than one are considered for further study while others are left out. Thus, the total factors in our case are 6. Also, it is to be noted that a Cumulative Variance \% between 60 and 70 is considered to be appropriate (which is 62.15 in our case). 
The next diagram is commonly called as the 'Scree Plot'. This is a plot of the calculated Eigen Values against the number of factors which have been extracted. The shape of this plot is significantly used when it comes to determining the actual factors to be considered. There is an evident break in this plot with an initial sharp slope of factors with Eigen value greater than one which is subsequently followed by a sprawling set of other factors. This gradual trailing off is referred to as the Scree and it has been proven that the point at which this Scree begins denotes the actual number of factors. However, it is to be kept in mind that the factors so determined are invariably one or more than the ones determined by the Eigen Value table. In our result, the point at which the trailing off begins is 8 ( 2 more than the factors which we got from the previous table). One of the most significant output of this exercise is the 'Component Matrix' table. However, the initial or the 'Un-rotated Factor Matrix' as it is termed may not be the most reliable output to be independently taken into account. This is because the initial solution generally witnesses a correlation between a single factor and many associated variables. Such results if obtained are difficult to interpret.

Thus, in order to simplify things, the 'Rotated Component Matrix' is taken into consideration which essentially rotates the original solution to ensure that the factors have significant loadings with only the relevant variables. Thus, using the results of the Rotated Component Matrix Table, we would place certain associated variables under the same umbrella. In order to do this, the researchers will have to predetermine a certain cut-off across components. For the study under consideration, the benchmark which has been set is 0.65 . Thus, all variables with a score above 0.65 (under a given component) would be clubbed under a common factor heading. The relevant factors and their subsequent variable/s thus identified include -

\section{Factor 1:-}

- Investment in Training and Development

- Variation in Routine Work

Factor 2:-

- Opportunities for International Work Assignments

- Size of Organization

- Employer Prestige in Marketplace

Factor 3:-

- Openness in Organization Culture

Factor 4:-

- Salary Hikes

Factor 5:-

- Workforce Diversity

- Work as per Pre-determined Schedule

Factor 6:-

- Scope for Creativity in Work Assigned

The 17 variables initially considered have been thus reduced to 10 relevant variables which span across 6 factors. The factors so framed are based on the opinion of the employees working in IT companies. The results thus signify the important variables that have a key role to play in placing a given employer brand at a superior position as against its counterparts.

The factors identified above can now be assigned suitable heads based on the initial literature review conducted.

Factor 1 - Variability in Job Setting and Overall Development/Empowerment

Factor 2 - Organizational Reputation and Flexibility

Factor 3 - Work Environment

Factor 4 - Compensation and Career Progression

Factor 5 - Workforce Assortment and Streamlined Job Activities

Factor 6 - Requisite Autonomy at Workplace

Apart from the above set of variables, an additional question was also asked to collect opinion regarding the positive impact of strategic employer branding initiatives in regards to retention levels within a firm. The rating was collected on a Likert Scale ranging from 'Very Relevant' to 'Extremely Irrelevant'. The results were as follows - 


\begin{tabular}{|c|c|c|}
\hline Rating & $\begin{array}{c}\text { Number of Responses } \\
\text { (out of 100) }\end{array}$ & Percentage of Responses (\%) \\
\hline 1- Very Relevant & 67 & 67 \\
\hline $2-$ Relevant & 30 & 30 \\
\hline $3-$ Neutral & 3 & 3 \\
\hline 4- Irrelevant & 0 & 0 \\
\hline 5- Extremely Irrelevant & 0 & 0 \\
\hline
\end{tabular}

The derivations from the factor analysis and the above result evidently support the pre-determined hypothesis which states that - 'Strategic Employer Branding reinforces the entire employment experience thereby positively influencing the retention levels within a firm'. The identified set of factors further help us point out the specific branding initiatives which have critical role to play in the mentioned arena.

The second set of questions were for students from premium management institutes in the city of Pune. The student questionnaire consisted of certain relevant variables which reinforce the fact that branding and advertising activities executed as part of the recruitment experience positively impact the candidate pool; thereby leading to better potential recruits. A total of eighteen such variables were considered and Factor Analysis was done on them (using the SPSS tool) in order to club these variables under broader factors. The intention has been to define certain relevant factors which if catered to, would result in definite attraction towards the latent employer. The variables that were considered as part of the employee survey are as follows -

1. Concern towards Employees

2. Investment in Training and Development

3. Job/Role Rotation Frequency

4. Openness in Organization Culture

5. Freedom to take-up Initiatives

6. Salary Hikes

7. Internal and External Equity in Pay Determination

8. Management Contribution towards Employees' Career Planning

9. Opportunities for International Work Assignments

10. Size of Organization

11. Stress - Free Work Environment

12. Employer Prestige in Marketplace

13. Scope for Creativity in Work Assigned

14. Social Media Presence (Networking through Facebook, Twitter, LinkedIn)

15. Word-of-Mouth Reputation through Ex-Employees

16. Print and Electronic Advertisements

17. Reach-out during Relevant Seminars, Conferences and Webinars

18. Prevalent Market Image as a Virtuous Employer

The 100 students who were surveyed belonged to versatile academic backgrounds and were asked to rate these variables in terms of their relevance towards creating the image of a virtuous employer. The ratings were given on a scale of 1 to 5 varying from Very Relevant to Irrelevant. These were then entered in SPSS to conduct Factor analysis. The result of the same is as follows-

\section{Factor Analysis}

KMO and Bartlett's Test

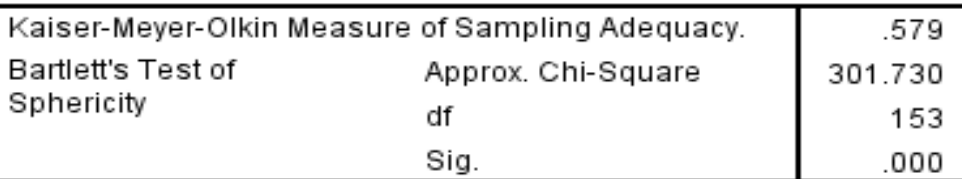




\begin{tabular}{|c|c|c|c|c|c|c|c|c|c|}
\hline \multicolumn{10}{|c|}{ Total Variance Explained } \\
\hline \multirow[b]{2}{*}{ Component } & \multicolumn{3}{|c|}{ Initial Eigenvalues } & \multicolumn{3}{|c|}{ Extraction Sums of Squared Loadings } & \multicolumn{3}{|c|}{ Rotation Sums of Squared Loadings } \\
\hline & Total & $\%$ of Variance & Cumulative \% & Total & $\%$ of Variance & Cumulative $\%$ & Total & $\%$ of Variance & Cumulative $\%$ \\
\hline 1 & 2.708 & 15.046 & 15.046 & 2.708 & 15.046 & 15.046 & 2.123 & 11.792 & 11.792 \\
\hline 2 & 2.154 & 11.967 & 27.013 & 2.154 & 11.967 & 27.013 & 2.101 & 11.673 & 23.464 \\
\hline 3 & 1.636 & 9.088 & 36.100 & 1.636 & 9.088 & 36.100 & 1.672 & 9.287 & 32.752 \\
\hline 4 & 1.425 & 7.917 & 44.018 & 1.425 & 7.917 & 44.018 & 1.457 & 8.094 & 40.846 \\
\hline 5 & 1.206 & 6.701 & 50.719 & 1.206 & 6.701 & 50.719 & 1.360 & 7.557 & 48.403 \\
\hline 6 & 1.157 & 6.428 & 57.147 & 1.157 & 6.428 & 57.147 & 1.341 & 7.452 & 55.855 \\
\hline 7 & 1.058 & 5.877 & 63.024 & 1.058 & 5.877 & 63.024 & 1.291 & 7.170 & 63.024 \\
\hline 8 & .998 & 5.547 & 68.571 & & & & & & \\
\hline 9 & .929 & 5.159 & 73.730 & & & & & & \\
\hline 10 & .797 & 4.428 & 78.158 & & & & & & \\
\hline 11 & .697 & 3.874 & 82.032 & & & & & & \\
\hline 12 & .629 & 3.496 & 85.528 & & & & & & \\
\hline 13 & .582 & 3.233 & 88.761 & & & & & & \\
\hline 14 & .515 & 2.861 & 91.622 & & & & & & \\
\hline 15 & .446 & 2.479 & 94.101 & & & & & & \\
\hline 16 & .397 & 2.204 & 96.306 & & & & & & \\
\hline 17 & .363 & 2.019 & 98.325 & & & & & & \\
\hline 18 & .302 & 1.675 & 100.000 & & & & & & \\
\hline
\end{tabular}

\begin{tabular}{|c|c|c|c|c|c|c|c|}
\hline \multicolumn{8}{|c|}{ Rotated Component Matrix } \\
\hline & \multicolumn{7}{|c|}{ Component } \\
\hline & 1 & 2 & 3 & 4 & 5 & 6 & 7 \\
\hline $\begin{array}{l}\text { ConcernTowardsEmploy } \\
\text { ees }\end{array}$ & .309 & -.012 & .269 & .440 & -.051 & -.451 & -.096 \\
\hline $\begin{array}{l}\text { InvestmentInTrainingAnd } \\
\text { Development }\end{array}$ & .016 & .475 & .649 & .014 & .074 & .009 & .026 \\
\hline $\begin{array}{l}\text { JobRoleRotationFrequen } \\
\text { cy }\end{array}$ & .112 & .544 & .216 & .364 & -.132 & -.144 & -.239 \\
\hline $\begin{array}{l}\text { OpennessInOrganization } \\
\text { Culture }\end{array}$ & -.020 & .072 & -.104 & .881 & .060 & .070 & .006 \\
\hline $\begin{array}{l}\text { FreedomToTakeUplnitiati } \\
\text { ves }\end{array}$ & -.246 & .238 & .497 & .372 & -.360 & -.050 & .168 \\
\hline SalaryHikes & -.051 & .468 & -.056 & .234 & .041 & -.430 & -.383 \\
\hline $\begin{array}{l}\text { InternalAndExternalEquity } \\
\text { InPayDetermination }\end{array}$ & .348 & .638 & -.019 & .055 & -.189 & .129 & -.147 \\
\hline $\begin{array}{l}\text { ManagementContribution } \\
\text { TowardsEmployeesCare } \\
\text { erPlanning }\end{array}$ & .448 & .425 & .115 & .043 & -.041 & .026 & .307 \\
\hline $\begin{array}{l}\text { OpportunityForinternation } \\
\text { alWorkAssignment }\end{array}$ & .659 & -.073 & -.353 & .293 & -.033 & .120 & .200 \\
\hline SizeOfOrganization & .813 & .068 & -.023 & -.071 & .070 & .083 & -.173 \\
\hline $\begin{array}{l}\text { StressFreeWorkEnvironm } \\
\text { ent }\end{array}$ & .296 & -.719 & -.051 & .070 & -.157 & .047 & -.110 \\
\hline $\begin{array}{l}\text { EmployerPrestigelnMarke } \\
\text { tplace }\end{array}$ & .621 & -.063 & .255 & -.080 & -.132 & -.299 & .143 \\
\hline $\begin{array}{l}\text { ScopeForCreativitylnWork } \\
\text { Assigned }\end{array}$ & .087 & -.082 & .697 & -.102 & .035 & .109 & .104 \\
\hline SocialMediaPresence & .085 & -.012 & .190 & .084 & -.113 & .845 & -.060 \\
\hline $\begin{array}{l}\text { WOMReputationThrough } \\
\text { ExEmployees }\end{array}$ & -.203 & .007 & .326 & .190 & .258 & .243 & -.099 \\
\hline $\begin{array}{l}\text { PrintAndElectronicAdverti } \\
\text { sements }\end{array}$ & .029 & -.039 & .099 & -.001 & .047 & -.039 & .859 \\
\hline
\end{tabular}




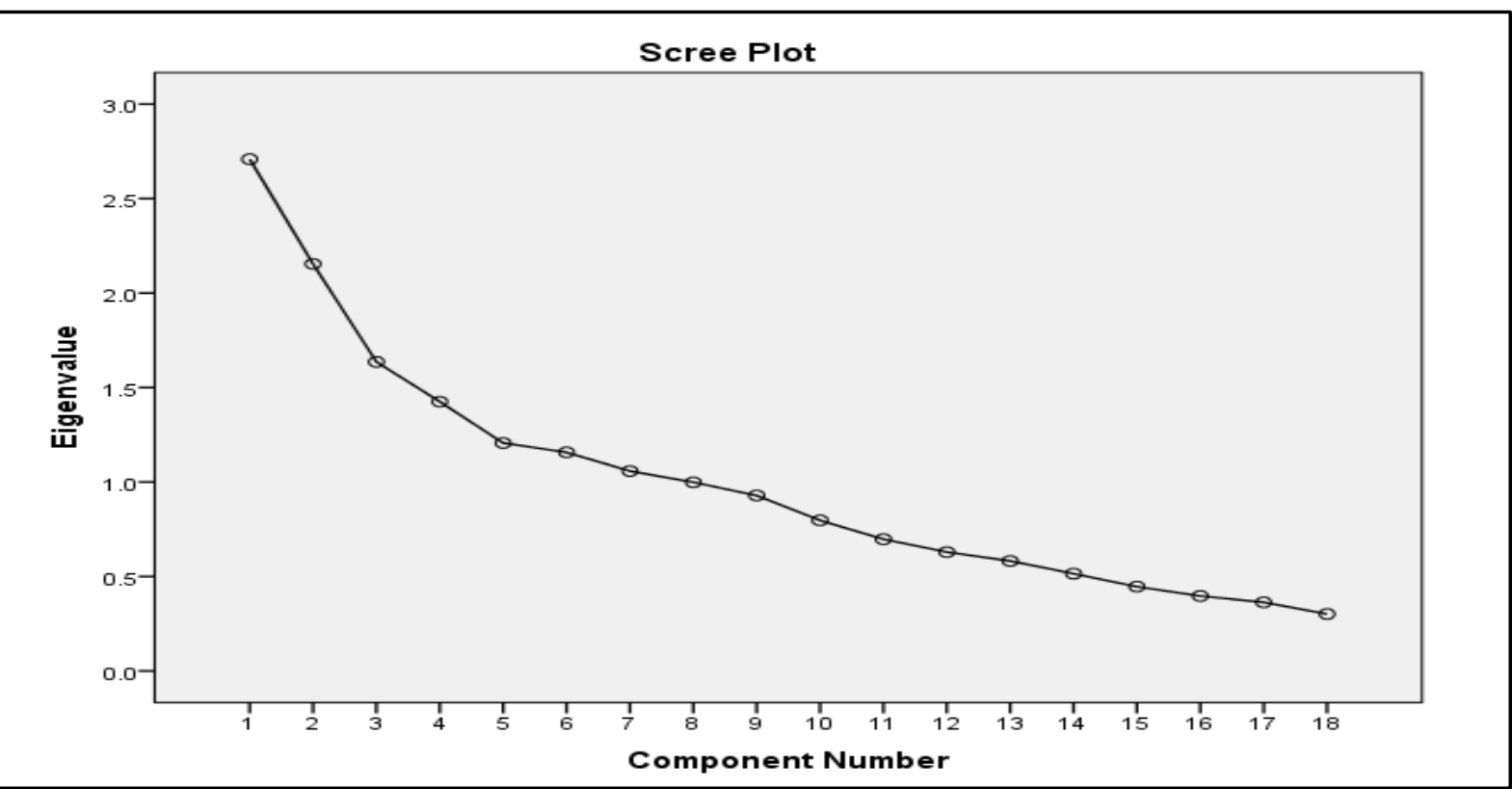

\begin{tabular}{|c|c|c|c|c|c|c|c|}
\hline $\begin{array}{l}\text { ReachOutDuringRelevant } \\
\text { SeminarsConferencesW } \\
\text { ebinars }\end{array}$ & -.052 & -.198 & .128 & -.002 & .782 & -.078 & -.074 \\
\hline $\begin{array}{l}\text { PrevalentMarketlmageAs } \\
\text { AVirtuousEmployer }\end{array}$ & .012 & .363 & -.095 & .028 & .648 & -.034 & .250 \\
\hline \multicolumn{8}{|c|}{$\begin{array}{l}\text { Extraction Method: Principal Component Analysis. } \\
\text { Rotation Method: Varimax with Kaiser Normalization. }\end{array}$} \\
\hline \multicolumn{8}{|c|}{ a. Rotation converged in 10 iterations. } \\
\hline
\end{tabular}

\section{Inferences:-}

A 'KMO' (Kaiser-Meyer-Olkin measure of sampling adequacy) value of 0.579 indicates that Factor Analysis is the relevant process to be conducted. The next important outcome is the 'Total Variance Explained' table. The 'Initial Eigen Values' / or simply Eigen Values given in the table are values that give us the variance explained by each factor. The variance attributed to each factor is in decreasing order of magnitude (as seen in the table). This is because the initial factors would be more dominant than the consequent trailing ones. Under this approach, only factors with values greater than one are considered for further study while others are left out. Thus, the total factors in our case are 7. Also, it is to be noted that a Cumulative Variance \% between 60 and 70 is considered to be appropriate (which is 63.02 in our case).

The next diagram is commonly called as the 'Scree Plot'. This is a plot of the calculated Eigen Values against the number of factors which have been extracted. There is an evident break in this plot with an initial sharp slope of factors with Eigen value greater than one which is subsequently followed by a sprawling set of other factors. In our result, the point at which the trailing off begins is 9 ( 1 more than the factors which we got from the previous table). One of the most significant output of this exercise is the 'Rotated Component Matrix' which essentially rotates the original solution to ensure that the factors have significant loadings with only the relevant variables. Thus, using the results of the Rotated Component Matrix Table, we would place certain associated variables under the same umbrella. In order to do this, the researchers will have to predetermine a certain cut-off across components. For the study under consideration (student data), the benchmark which has been set is 0.6. Thus, all variables with a score above 0.63 (under a given component) would be clubbed under a common factor heading. The relevant factors and their subsequent variable/s thus identified include - 
Factor 1:-

- Size of Organization

Factor 2:-

- Internal and External Equity in Pay Determination

Factor 3:-

- Investment in Training and Development

- Scope for Creativity in Work Assigned

Factor 4:-

- Openness in Organization Culture

Factor 5:-

- Reach-out during Relevant Seminars, Conferences and Webinars

- Prevalent Market Image as a Virtuous Employer

Factor 6:-

- Social Media Presence

Factor 7:-

- $\quad$ Print and Electronic Advertisements

The 18 variables initially considered have been thus reduced to 9 relevant variables which span across 7 factors. The factors so framed are based on the opinion of the students currently studying in management institutes in the city of Pune. The results thus signify the important variables that have a key role to play in placing a probable employer brand at a superior position as against its competitors.

The factors identified above can now be assigned suitable heads based on the initial literature review conducted.

Factor 1 - Organizational Reputation

Factor 2 - Compensation and Career Progression

Factor 3 - Requisite Autonomy at Workplace and Overall Development/Empowerment

Factor 4 - Work Environment

Factor 5 -Promotional Initiatives by a Firm and Righteousness of Potential Employer

Factor 6 - Brand Endorsement in Virtual World

Factor 7 -Extensive Marketing Strategies to Attract Future Incumbents

Apart from the above set of variables, an additional question was also asked to collect opinion regarding the critical role that enhanced recruitment experience plays in attracting a better talent pool. The rating was collected on a Likert Scale ranging from 'Very Relevant' to 'Extremely Irrelevant'. The results were as follows -

\begin{tabular}{|c|c|c|}
\hline Rating & $\begin{array}{c}\text { Number of Responses } \\
\text { (out of 100) }\end{array}$ & Percentage of Responses (\%) \\
\hline 1- Very Relevant & 77 & 77 \\
\hline $2-$ Relevant & 23 & 23 \\
\hline 3- Neutral & 0 & 0 \\
\hline 4- Irrelevant & 0 & 0 \\
\hline 5 - Extremely Irrelevant & 0 & 0 \\
\hline
\end{tabular}

The derivations from the factor analysis and the above result evidently support the pre-determined hypothesis which states that - 'Branding and advertising activities executed as part of the recruitment experience positively impact the candidate pool; thereby leading to better potential recruits'. The identified set of factors further help us point out the specific branding initiatives which have critical role to play in the mentioned arena.

\section{Significance ofthe Outcome:-}

Organisations have profusely used marketing and branding practices to stimulate product/service brand loyalty in customers. Building up on similar lines, firms today are intensifying this activity to further distinguish themselves as against their counterparts, thereby making them desirable employers in the eyes of their current and/or plausible workforce. Through this dissertation, we attempted to highlight the need for IT organisations to strategically align their HR function, most specifically functions like recruitment, learning and development, and marketing/communication, in order to build the image of a an admired employer thereby resulting in enhanced attraction and retention levels. 
The researchers have tried to point out that if managers at the planning and execution level in IT organizations try to focus their energies on the identified set of factors, it would definitely facilitate them to uplift the stature of their respective organizations. Finally, this synergic initiative would aid the firms to be branded with the title of 'Employer of Choice', subsequently elevating their financial standing as well.

\section{Conclusion and Recommendations:-}

At a broader level, firms have been seen to realise the significance of building a strategic employer brand. This understanding has been proven by the fact that organizations today are expending a substantial amount to expand the realm of employer branding. The intention is crystal clear; invest in attracting the best talent pool in the industry, employ streamlined initiatives to retain them and consequently ensure that there is economic value add out of the entire exercise. Further, successfully attracting the best minds in the industry gives the firm an evident edge over its competitors.

At an individualistic level, the benefits of employer branding are again manifold. Potential recruits rely on their personal perceptions about a brand or the generic word of mouth while evaluating the pros and cons of being associated with a potential employer. There are off course certain other evident benefits of establishing an Employee Value Proposition. The first and foremost being the ability to curb the total time taken to fill in a position. Since an established brand automatically attracts decent quality talent, the ensued time required for advertising and related search activities is cut down by a great extent. The next important dimension is that of the cost per hire. A targeted brand promise helps in enticing the right talent pool, thereby plummeting the need for employee referral. As recruitment related expenditures are done within a certain pre-determined amount of budget, the reduced cost per hire turns out to be significantly beneficial. Further, during adverse trade cycles, such as a situation of recession, an appealing employer brand warrants that the current workforce is retained, thereby contributing towards financial stability. Finally, since the umbrella of employer branding also entails eminent learning and development initiatives, it is consequently ensured that the overall 'quality of hire' is enriched; thereby guaranteeing better client servicing by the organization.

Another point to be noted here is that since bulk of the operational costs $(65 \%-70 \%)$ comprise of human resource related expenditure, curbing it down would inevitably make sure that the business is profitable. It is thus imperative to understand that even peripheral improvement in attraction and retention levels would facilitate long term sustainability of the firm.

In this study, we tried to capture the perceived importance of varied psychographic factors. To do the same, a sample of both employed and unemployed (seeking job opportunities) personal was taken. Each of these individuals were asked to rate each of the variables considered, in regards to their relative importance, on a multi-rating scale. Further, through exploratory factor analysis (principal component method), the significant dimensions in regards to employer attractiveness and employee retention, were brought to light.

Factors such as Variability in Job Setting, Overall Development/Empowerment, Organizational Reputation, Flexibility, Compensation and Career Progression emerged to be dominant factors across the sample size considered. This is reflective of the fact that the workforce of today demands autonomy at workplace and adequate space to be creative in their daily tasks and responsibilities. Further, corporate image and prestige in marketplace was observed to be a substantial determining factor for an employee's decision regarding pursuance of any employment. Also, a significant number of respondents were seen to be in agreement with the stated hypothesis, thereby certifying the relevance of the research conducted. These results therefore have pertinent managerial implications and can be thought provoking as far as human resource management is concerned. Hence, comprehending the versatile preferences of impending job hunters, would enable the line managers to be proactive in their approach and ensure that productive employment messages are adequately conveyed, as and when required. 
The above discussions can be illustrated with the help of the following framework -
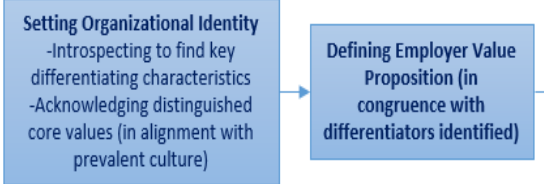

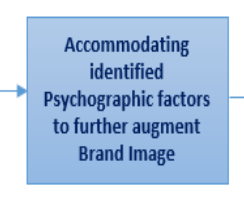

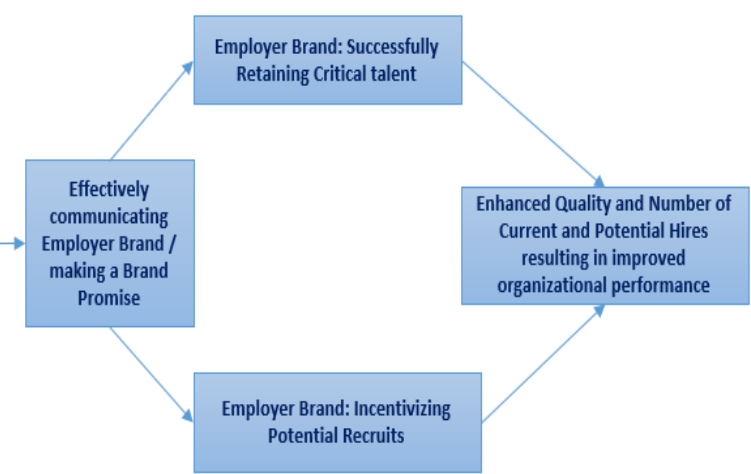

Finally, it needs to be acknowledged that the study had certain limitations. The research sample consisted of two broad segments - employees working in four renowned IT Corporates and job seekers who were currently pursuing a management degree across five celebrated institutes, in the city of Pune. Thus, it is suggested that further study in this regard should be inclusive of an even more representative sample so that generalizations about a set of population could be made. Also, the research scope could be enhanced beyond the variables: attraction, retention and could include relevant dimensions such as employee satisfaction. Furthermore, the statistical means used could be expanded to incorporate a confirmatory factor analysis.

\section{References:-}

1. Agrawal, R. \& Swaroop, P. (2009). Effect of employer brand image on application intentions of B-school undergraduates. The Journal of Business Perspective, 13(3), pp.41-49

2. Alnıaçık, E., \& Alnıaçık, Ü. (2012). Identifying dimensions of attractiveness in employer branding: effects of age, gender, and current employment status. Procedia-Social and Behavioral Sciences, 58, 1336-1343.

3. Amby, L. MAKING SENSE OF EMPLOYER BRANDING IN THE PUBLIC SECTOR.

4. Aslam, S. (2015). Employer branding and intention to apply by usage of social media in banking sector, Pakistan. International Journal of Scientific \& Engineering Research, 6(5), 400-405.

5. Baloch A.,Awan S.(2012).Impact of Employer-Brand Equity Promotion for effective talent recruitment of fresh graduates in Pakistan. African Journal of Business Management Vol.6 (44), pp. 10906-10924, 7 November 2012

6. Bakanauskienè, I., Bendaravičienè, R. Krikštolaitis, R. Lydeka, Z. (2011). Discovering an Employer Branding: Identifying Dimensions of Employer's Attractiveness in University, Management of Organizations: Systematic Research, 59, pp. 7-22

7. Backhaus, K., \& Tikoo, S. (2004). Conceptualizing and researching employer branding. Career development international, 9(5), 501-517.

8. Berthon P.,Ewing M (2005). Captivating company: dimensions of attractiveness in employer branding. International Journal of Advertising, 24(2), pp. 151-172

9. Buttenberg K. (2013).The impact of Employer Branding on Employee Performance.New Challenges of Economic and Business Development. May 9 - 11, 2013,

10. Collins, C.J., \& Han, J. (2004). Exploring applicant pool and quality: The effects of early recruitment practices, strategies, corporate advertising, and firm reputation. Personnel Psychology, 57, 685-717.

11. Davies, G. (2008). Employer Branding and its Influence on Managers, European Journal of Marketing, 42,(6), pp.667-681

12. Dawn S.,Biswas S. (2010). Employer branding: A new strategic dimension of Indian corporations.Asian Journal of Management Research ISSN 2229-3795

13. Della Corte, V., Mangia, G., Micera, R., \& Zamparelli, G. (2011). Strategic Employer Branding: the brand and image management as attractiveness for talented capital. China-USA Business Review, 10(12).

14. Esra,Umit (2012). Identifying Dimensions of Attractiveness in Employer Branding: Effects of Age, Gender, and Current Employment Status.Procedia-Social and Behaviourial Sciences, Volume 58 
15. Fulmer, I., \& Gerhart, B., et al. (2003). Are the 100 best better? An empirical investigation of the relationship between being a 'great place to work' and firm performance. Personnel Psychology, 56, 965-993.

16. Gupta P., (2014) Employer Branding: A Descriptive Study. International Journal of Economic and Management Strategy. ISSN 2278-3636 Volume 4, Number 1 (2014), pp. 1-10

17. Jenner, S. and Taylor, S. (2009). Employer branding-fad or the future of HR? CIPD London

18. Karkhanis, T. A. Impact of Employer Branding and Applicants' Intentions to Apply.

19. K. Ito, J., M. Brotheridge, C., \& McFarland, K. (2013). Examining how preferences for employer branding attributes differ from entry to exit and how they relate to commitment, satisfaction, and retention. Career Development International, 18(7), 732-752.

20. Leekha Chhabra, N., \& Sharma, S. (2014). Employer branding: strategy for improving employer attractiveness. International Journal of Organizational Analysis, 22(1), 48-60.

21. Lievens, F., \& Highhouse, S. (2003). The relation of instrumental and symbolic attributes to a company's attractiveness as an employer, Personnel Psychology, 56(1), pp.75-102

22. Mandhanya, Y. \& Shah, M. (2010). Employer Branding-A tool for talent management, Global Management Review, 4(2), pp.43-48

23. Moroko, L., \& Uncles, M. D. (2008). Characteristics of successful employer brands. Emerald Management Reviews, 16(3): 160-175.

24. Oladipo T.,Otubanjo O.(2013). Employer Branding: Moulding Desired Perceptions in Current and Potential Employees. Journal Of management and sustainability,Vol. 3,No. 3

25. Pingle, S. S., \& Sharma, A. (2013). External Employer Attractiveness: A Study of Management Students in India. Journal of Contemporary Management Research, 7(1).

26. Priyadarshi, P. (2011). Employer brand image as predictor of employee satisfaction, affective commitment \& turnover. Indian Journal of Industrial Relations, 510-522.

27. Rajkumar, V. S., PadManand, V., Ganesan, P., \& VenuGoPal, P. (2015). Employer Branding Dimensions--A Discriminate Analysis Approach In Campus. Global Management Review, 10(1).

28. Ritson, M. (2002). "Marketing and HE Collaborate to Harness Employer Brand Power", Marketing, 24, October, 24

29. Sivertzen, A. M., Nilsen, E. R., \& Olafsen, A. H. (2013). Employer branding: employer attractiveness and the use of social media. Journal of Product \& Brand Management, 22(7), 473-483.

30. Theurer, C. P., Tumasjan, A., Welpe, I. M., \& Lievens, F. (2016). Employer Branding: A Brand Equity-based Literature Review and Research Agenda. International Journal of Management Reviews.

31. Tüzüner, V.L. \& Yüksel, C.A., (2009). Segmenting Potential Employees According to Firms' Employer Attractiveness Dimensions in The Employer Branding Concept, Journal of Academic Research in Economics, 1(1), pp.46-61

32. Van Dam, N. (2006). Building an employer brand through investments in learning. Chief Learning Officer, $5(6), 13$.

33. Vijayalakshmi, V., \& UTHAYASURIYAN, K. (2016). The Impact of Employer Branding on Employee Performance. Indian Journal of Applied Research, 5(8).

34. Wilden, R.M., Gudergan, S. \& Lings, I.N. 2010, 'Employer branding: strategic implications for staff recruitment', Journal of Marketing Management, vol. 26, no. 1-2, pp. 56-73

\section{Glossary:-}

1. Employer Brand - In this context, the term means becoming 'the employer of choice' by promoting unique benefits as part of the employment experience, subsequently enhancing the value proposition for existing and potential employees.

2. Employer Attractiveness is defined as the envisioned benefits that a potential employee sees in working for a specific organization. The objective is to enable the firm to gain a competitive edge in the labour market.

3. Retention, in this background, encompasses those employees who are willing to stay in an organization for a period greater than two years because they trust the employees they work for and take conceit in the work they do. 